\title{
Formulation and implementation of a practical multi-surface soil plasticity model
}

S Whyte ${ }^{1^{*}+}, \mathrm{H}$ J Burd ${ }^{+}$and C M Martin ${ }^{+}$, M Rattley $^{*}$

${ }^{+}$Department of Engineering Science, University of Oxford, Parks Road, Oxford, OX1 3PJ, UK

*Fugro GB Marine Limited, Wallingford, Oxfordshire, OX10 9RB, UK

${ }^{1}$ Corresponding author: scott.whyte@eng.ox.ac.uk

\begin{abstract}
This paper presents a new constitutive model for clay, for undrained monotonic and cyclic loading, that has been developed specifically for geotechnical design applications. The model employs a parallel Iwan approach, consisting of multiple elastic-perfectly-plastic micro models. Degradation of stiffness and strength during cyclic loading is incorporated using an empirical cyclic overlay method. The theoretical framework and calibration processes for the model are presented. An implementation of the model in a commercial finite element program is then described; this implementation is demonstrated via 3D finite element analyses of example offshore monopile foundations subjected to monotonic and cyclic lateral loading.
\end{abstract}

Keywords: Undrained clay, Monopile, Offshore foundation, Cyclic loading, Constitutive model, Parallel Iwan model 


\section{INTRODUCTION}

Various advanced constitutive models have been proposed to capture the behaviour of clay for monotonic and cyclic loading. MIT-E3 (Whittle and Kavvadas, 1994), 3SKH (Stallebrass and Taylor, 1997), SANICLAY (Dafalias et al., 2006) and B-SCLAY1S (Sivasithamparam, 2012) are examples of sophisticated effective stress constitutive models that can replicate many of the key trends observed in the monotonic and cyclic response of clay. However, uptake of such models by practising geotechnical engineers has remained low. It is considered that this is due to the inherent complexity of effective stress models of this sort, and also because the model parameters are often difficult to calibrate using soil data acquired in typical geotechnical site investigations. For example, the undrained shear strength $\left(s_{u}\right)$ is not a direct input for such models; it depends on various other parameters and model features, such as: the assumed coefficient of earth pressure at rest $\left(\mathrm{K}_{0}\right)$, the overconsolidation ratio $(\mathrm{OCR})$, the stress-dilatancy response, the initial void ratio, the critical state friction angle and, where relevant, approaches employed to model anisotropy and destructuration. This is a significant disadvantage for analyses involving short-term loading of clays, for which prescribed undrained shear strength profiles are a preferred input.

The analysis of offshore monopile foundations under undrained cyclic lateral loading is a design application where three-dimensional (3D) finite element analysis (FEA) can be usefully applied in practice. Although examples of such cyclic analyses can be found in the research literature (e.g. Corciulo et al., 2017) these analyses are typically limited to a relatively small number of cycles. Possible reasons for this include the prevalence of numerical convergence issues and lengthy run times, particularly when effective stress models are used. For example, Haiderali et al. (2015) used a subloading-type effective stress constitutive model to perform fully coupled flow-deformation 3D FEA of a laterally loaded monopile in clay, but only 12 cycles of relatively low amplitude loading could be applied because of the high computational cost.

In design situations involving short-term loading of a foundation embedded in a clay soil, total stress constitutive models are an attractive option for use in FEA, as an alternative to effective stress approaches. Total stress models provide a means of specifying undrained shear strength as a model input parameter. Additionally, they tend to be simpler to implement, faster to compute and more stable than advanced effective stress models. However, there are few examples in the literature of total stress models that can realistically capture the salient features of the response of undrained clay 
under both monotonic and cyclic loading. For monotonic loading, a simple isotropic hardening Tresca or von Mises model, typically available as a standard built-in model in commercial FEA codes, is a popular choice for practising engineers. More advanced total stress models such as NGI-ADP (Grimstad et al., 2012) and AUS (Kouretzis et al., 2017) offer higher fidelity predictions of the monotonic stress-strain response, but they are not suitable for capturing the hysteretic unload-reload response, or any strength and stiffness changes that may develop during cyclic loading.

From a practical design perspective, there is therefore an ongoing need for total stress constitutive models that are suitable for simulating monotonic and cyclic loading of undrained clay. Such models should ideally (i) be straightforward to implement (ii) have parameters that can be calibrated using data from typical geotechnical site investigations (iii) facilitate efficient and stable computations of boundary value problems using 3D FEA. This paper presents a model, termed the 'Parallel Iwan MultiSurface' (PIMS) model, that offers these characteristics. It is developed as a hierarchical model in which cyclic behaviour can be activated or deactivated depending on the analysis being performed.

The current model was primarily developed for implementation in a FEA program to predict the performance of offshore foundations in clay soils during, and immediately after, short-term storm-type cyclic loading events. The model is capable of capturing (i) nonlinear stiffness response from very small to large strains for different stress paths (ii) different undrained shear strengths for different stress paths (iii) effects of recent stress history (iv) hysteretic unload-reload response (v) cyclic degradation of stiffness and strength. Rate effects typically also need to be considered when calibrating and using a constitutive model for clay for cyclic loading. In the current model, rate effects are included in a rudimentary way, by scaling the model parameters to develop a family of ratecorrected normalised stress-strain curves.

The paper begins with an overview of the important features of the behaviour of undrained clay under monotonic and cyclic loading, as observed in laboratory testing. The theoretical framework and implementation process for the proposed constitutive model are then provided, together with an overview of the parameter calibration procedure. The model is implemented in a commercial finite element program (PLAXIS) and this implementation is demonstrated via a case study based on recently published pile load tests in overconsolidated clay, for monotonic lateral loading. Finally, calibration of the model to cyclic laboratory test data is presented, together with an example 3D FEA 
of a large-diameter offshore monopile under cyclic lateral loading, for a representative storm loading history. 


\section{EXPERIMENTAL AND MODELLING BACKGROUND}

\subsection{Experimental observations}

\subsubsection{Monotonic behaviour}

The pre-failure stress-strain response of soil is highly nonlinear. For monotonic loading of clay, the variation of tangent and secant shear modulus $\left(G_{\mathrm{tan}}\right.$ and $\left.G_{\mathrm{sec}}\right)$ with the logarithm of shear strain, $\gamma$, typically follows an S-shaped curve (Clayton, 2011; Vardanega and Bolton, 2013) with the small-strain shear modulus $\left(G_{0}\right)$ representing a plateau at very small shear strains $\left(\gamma<10^{-5}\right)$. For practical design applications, it is advantageous if constitutive models can be calibrated directly to this stiffness variation curve (referred to as the 'stiffness backbone curve') or the parent stress-strain curve ('stressstrain backbone curve'). It has been shown that these (inter-related) curves are strain rate dependent (e.g. Sheehan et al., 1996; Torisu et al., 2012), and the most appropriate backbone curve for use in a particular context depends on the loading rate in the problem being modelled. The backbone curve is also known to depend on factors such as structure (i.e. the combined effect of fabric and inter-particle forces), the recent stress history (i.e. stress history in which consolidation, creep and ageing effects are not considered), and the imposed stress path (e.g. Prevost, 1977; Ladd, 1991; Grimstad et al., 2012).

The dependency of the backbone curve on the stress path can be observed by comparing the results of undrained triaxial compression (CUc), undrained triaxial extension (CUe), and undrained direct simple shear (UDSS) laboratory tests on clay samples having the same initial state; the backbone curves for these tests are typically significantly different. Laboratory element test data presented in the literature show that the angle, $\alpha$, of the major principal stress, $\sigma_{1}$, with respect to the sample axis and the value of the intermediate principal stress ratio, $\zeta=\frac{\sigma_{2}-\sigma_{3}}{\sigma_{1}-\sigma_{3}}$, has a significant effect on the overall mechanical response of clay (e.g. Grimstad et al., 2012). The stress-strain backbone curve, as well as the shear strength, has been shown to be stress path dependent for clay, with a significantly softer response in triaxial extension $\left(\alpha=90^{\circ}, \zeta=1\right)$ than triaxial compression conditions $\left(\alpha=0^{\circ}, \zeta=0\right)$.

A comparison of the measured undrained shear strength, $s_{\mathrm{u}}$, in different types of laboratory test is often cited as a measure of the 'strength anisotropy' of the clay; however, this terminology is potentially misleading when used to describe a general stress path dependency. As noted by Kouretzis et al. (2017), an isotropic model may exhibit different $s_{\mathrm{u}}$ values for triaxial compression and 
extension tests due to the yield strength in the deviatoric plane being dependent on Lode angle $(\theta)$. For example, when the Mohr-Coulomb yield function, or similar, is used in an effective stress model, different strengths in triaxial compression and extension are predicted even though the model is isotropic. The Tresca yield function incorrectly predicts the same undrained strength for all shearing stress paths, but is routinely employed in isotropic total stress models for clay. Additionally, experimentalists have shown (e.g. Callisto and Calabresi, 1998; Nishimura et al., 2007) that naturally deposited clays often exhibit anisotropic properties caused by their structural fabric arrangement (inherent anisotropy) and current stress conditions (induced anisotropy). Therefore, for a total stress constitutive model, it is desirable to be able to define an isotropic yield surface shape with Lode angle dependency, and to incorporate anisotropy separately, if necessary and if suitable calibration data are available.

\subsubsection{Cyclic behaviour}

Fig. 1 shows a schematic diagram of an idealised response observed in a symmetrical, strain controlled, 2-way cyclic triaxial test conducted on a sample of undrained clay. This figure employs the conventional triaxial parameters; deviatoric stress, $q=\sigma_{\mathrm{a}}-\sigma_{\mathrm{r}}$, and triaxial shear strain, $\varepsilon_{q}=\frac{2}{3}\left(\varepsilon_{a}-\right.$ $\varepsilon_{r}$ ), where the subscripts $a$ and $r$ denote the axial and radial directions (compression positive) respectively. Initially (Point A), the sample is isotropically consolidated. The sample is then loaded to Point B and a single unload-reload cycle is applied (cycle 1 on Fig. 1). The first cycle secant shear modulus $G_{s e c, 1}$ is defined as shown in the figure. Further strain cycles are then applied; Fig. 1 shows the $N^{\text {th }}$ cycle. These strain cycles cause the secant shear modulus to reduce to $G_{s e c, N}$, with an associated reduction in strength (compare the 'backbone curve' with the 'cyclically degraded backbone curve' in Fig. 1). In previous studies (e.g. Vucetic and Dobry, 1988; Okur and Ansal, 2007; Andersen, 2015; Wichtmann and Triantafyllidis, 2017); these observed reductions in stiffness and strength during cyclic loading - collectively referred to in this paper as 'cyclic degradation' - were attributed to the combined effect of destructuration and pore pressure accumulation.

Various empirical cyclic models for undrained clay have been developed (e.g. Idriss et al., 1978). These typically link cycle number, $N$, to a 'degradation factor' that is applied to the loads/stresses to determine a cyclically degraded backbone curve (thus reducing both the stiffness and strength). Although these simple empirical cyclic degradation models have been used extensively by practising geotechnical engineers (e.g. Andersen, 2015), they fail to capture the detailed response within 
individual cycles and are applicable only to the stress path for which they have been developed; they therefore may not be suitable for multiaxial cyclic loading. Vucetic and Dobry (1988) showed that using accumulated deviatoric strain, as opposed to cycle number, to control the rate of degradation in the model allows this approach to be applied more generally to different test configurations, and permits empirical cyclic extensions to be implemented within elasto-plastic constitutive models.

The rate of cyclic degradation has been shown to depend on various factors. For example, the degree to which the backbone curve has been mobilised prior to unloading, and the strain amplitude of each cycle, significantly affect the rate of cyclic degradation (e.g. Vucetic and Dobry, 1988; Lefebvre and Pfendler, 1996; Andersen, 2015). Vucetic and Dobry (1988) also showed that the rate of cyclic degradation is influenced by the initial overconsolidation ratio (OCR). The effect of OCR on the rate of cyclic degradation has been discussed by many authors (e.g. Hyde and Ward, 1986; Yasuhara et al., 2003; Thian and Lee, 2017). Additionally, Vucetic (1994) and Mortezaie and Vucetic (2016) showed that below a certain shear strain value, termed the 'cyclic threshold shear strain', cyclic degradation does not occur to any significant degree. The magnitude of the cyclic threshold strain value is typically considered to be unaffected by the previous cyclic loading history.

It has been shown extensively in the literature that the small-strain shear modulus, $G_{0}$, is dependent on the current mean effective stress (e.g. Hardin and Black, 1968); $G_{0}$ would therefore be expected to reduce during undrained cyclic loading when positive pore pressures accumulate. However, bender element tests performed in undrained cyclic triaxial tests, reported by Gu et al. (2014), on two remoulded clays from eastern China, showed that $G_{0}$ degrades significantly more rapidly during cyclic loading than would be expected solely on the basis of a reduction in the effective stresses.

In summary, according to previous experimental studies, the salient features of the undrained cyclic response of saturated clay are:

i. A reduction in secant stiffness and strength with number of cycles (cyclic degradation) occurs, unless the strain amplitude is below a certain threshold value.

ii. The small-strain shear modulus $G_{0}$ has also been shown to degrade with number of cycles.

iii. The rate of cyclic degradation depends on the cyclic strain amplitude and the degree to which the backbone curve has been previously mobilised.

iv. The rate of cyclic degradation depends on the OCR. 


\subsection{Modelling approaches}

\subsubsection{Multi-surface modelling overview}

Total stress constitutive models which only include a single isotropic hardening yield surface (e.g. Grimstad et al., 2012) are not suitable, without applying complex nonlinear elastic rules within the yield surface, for capturing the hysteretic unload-reload response of clay. An elasto-plastic model with linear kinematic hardening can be used to simulate a Masing-type response, although a single kinematic hardening yield surface lacks the resolution required to predict realistic soil behaviour (Houlsby, 1999). A common approach for overcoming such issues is to use a 'bounding surface' model, though as discussed by Houlsby (1999), such models must include complex, somewhat arbitrary, mapping rules to control their behaviour and often lack the ability to capture recent stress history effects accurately. Therefore, an elasto-plastic model incorporating multiple yield surfaces is preferred. Multi-surface models are typically implemented using several nested kinematic hardening yield surfaces (e.g. Prevost, 1977; Houlsby, 1999; Elgamal et al., 2003). The individual yield surfaces translate in stress space when they are activated, such that all active yield surfaces are at the same stress condition. Such models can be termed 'series Mroz-Iwan' models after the seminal work of Mroz (1967) and Iwan (1967). Despite offering an elegant modelling approach for simulating a nonlinear hysteretic response, tensorial series Mroz-Iwan models can become complex and implementation can be difficult.

Chiang and Beck (1994), Einav and Collins (2008) and Grimstad et al. (2014) have demonstrated that the use of multi-surface models based on a 'parallel Iwan' approach, as first proposed by Iwan (1966), offers a method that is simpler to develop and implement, while still providing a predictive capability similar to that of the series Mroz-Iwan approach. Iwan (1966) proposed a one-dimensional (1D) model in which a number of spring-slider elements, with different yield strengths and different elastic stiffnesses, are arranged in parallel. The model assumes strain equivalence across all of the springslider elements. Following an increment of strain, the resulting stress from the model (termed 'macro stress') is determined from a weighted sum of the individual stresses (termed 'micro stresses') in the spring-slider elements. Fig. 2 illustrates a 1D parallel Iwan model with three spring-slider elements. Virtual experiments performed by Einav and Collins (2008) showed that the parallel Iwan modelling approach has clear micromechanical physical meaning, and the model parameters can be directly related to the statistical distribution of strength in a representative volume of soil. 
When the parallel Iwan approach is adopted as the basis of a continuum plasticity model, a set of individual constitutive models, here termed 'micro models', are specified in parallel. Typically, and in the model developed in this paper, each micro model is an elastic-perfectly-plastic model, i.e. with a single stationary yield surface. All of the micro models are subjected to the same strain history, with the macro stress tensor $(\boldsymbol{\sigma})$ calculated as,

$$
\boldsymbol{\sigma}=\sum_{i=1}^{n} w_{i} \boldsymbol{\sigma}_{\text {micro }}
$$

where $n$ is the number of micro models and $w_{i}$ is the weight of each micro models' stress tensor, $\boldsymbol{\sigma}_{\text {micro }}$, with the sum of the weights constrained to be unity (i.e. $\sum w_{i}=1$ ). As discussed by Einav and Collins (2008), from a micromechanical perspective it is preferable for all micro models to have the same stiffness and to specify the desired backbone behaviour by employing different yield strengths and weights for the micro models. In a practical implementation of the model, a choice needs to be made on the number of micro models, $n$, to be employed. If $n$ is large, then the computer time and storage requirements may become excessive. Alternatively, if a relatively small number of micro models is chosen, then the modelled stress-strain response will not be smooth and therefore unrepresentative of reality. In the current paper, the yield strength of each micro model is specified to increase monotonically with micro model index $i$.

Fig. 3 illustrates the response of an example parallel Iwan model with four von Mises micro models, for a strain controlled cyclic triaxial test. It is apparent that the stress state of each micro model is different from that of the overall model (the macro stress); indeed the latter may lie outside some of the micro model yield surfaces. It is important to note, however, that the consistency condition is fulfilled for all micro models, i.e. the micro stresses are constrained to remain on their micro yield surfaces during plastic deformation. This example demonstrates how several simple micro models in a parallel Iwan arrangement can produce a Masing-type nonlinear hysteretic response without the need for translating yield surfaces.

A major advantage of using a parallel Iwan approach is that each micro model is implemented in the same manner as any other single surface perfect plasticity model. As a result, any single-surface constitutive model that has been implemented as a user-defined soil model can be extended to a multi-surface model by applying a relatively simple parallel Iwan 'wrapper' code. This is a significant advantage, as despite the benefits of multi-surface models, the complexity of implementation is often 
considered to be a barrier. The parallel Iwan approach is therefore adopted for the development of the PIMS model presented in this paper.

\subsubsection{Cyclic degradation}

Incorporating a cyclic degradation overlay within a constitutive model, in which the stiffness and strength are degraded as a function of accumulated deviatoric strain, offers a simple way of capturing cyclic loading behaviour that is consistent with the established cyclic degradation approach described in Section 2.1.2. Huang and Liu (2015) presented such an approach in which a simple cyclic degradation rule, based on accumulated plastic deviatoric strain, was applied to a kinematic hardening von Mises model and used to perform FEA of cyclic axial loading of piles in clay. A similar approach (although employing the sum of the plastic and elastic deviatoric strains to control the degradation behaviour) is employed in the PIMS model.

Iwan and Cifuentes (1986) extended the parallel Iwan approach to develop a 1D model capable of simulating the degrading hysteretic response of structures subjected to earthquake motions, by including the effects of stiffness and strength degradation. This model incorporated additional deteriorating elastic-plastic elements in parallel with standard elastic-plastic elements. The additional deteriorating elements were similar to the standard (non-degrading) elements, but were set to 'break' when the strain exceeded a prescribed threshold for that element. Once broken, the relevant elements were removed from the model. A similar approach is adopted in the PIMS model. However, rather than the sudden breakage adopted by Iwan and Cifuentes (1986), there is gradual 'breakage' of the micro models, achieved by reducing their weights, based on the accumulation of a deviatoric strain measure during cyclic loading. This allows various detailed features of the soil response to be captured. 


\section{FORMULATION AND IMPLEMENTATION OF THE PIMS MODEL}

This section first presents the formulation of the elastic-perfectly-plastic model that is used for each micro model in the parallel Iwan arrangement. The multi-surface formulation is then explained, followed by the cyclic degradation extension. The adopted sign convention is compression positive.

\subsection{Micro model formulation}

Since the model is developed for undrained conditions, the yield $(f)$ and plastic potential $(g)$ functions are independent of the mean stress. This form of the plastic potential ensures zero plastic volumetric strain. Linear elasticity based on the small-strain elastic shear modulus $G_{0}$, and a Poisson's ratio of 0.495 is adopted for the elastic component of the model. The yield function for each micro model is,

$$
f=\sqrt{\frac{3}{2} \mathbf{s}: \mathbf{s}}-m
$$

where $\mathbf{s}$ is the deviatoric stress tensor given by,

$$
\mathbf{s}=\boldsymbol{\sigma}-p \mathbf{I}
$$

in which $\boldsymbol{\sigma}$ is the micro stress tensor, $\mathbf{I}$ is the second order identity tensor and $p=\frac{1}{3} \operatorname{tr} \boldsymbol{\sigma}$. The 'yield strength' $m$ is,

$$
m=q_{u c} R(\theta)
$$

where $q_{u c}$ is the deviator stress yield strength in triaxial compression for the micro model, and $R(\theta)$ is a function that controls the shape of the yield surface in the deviatoric plane. Here the $R(\theta)$ function proposed by Sheng et al. (2000) is used,

$$
R(\theta)=\left(\frac{2 \beta^{4}}{1+\beta^{4}+\left(1-\beta^{4}\right) \sin 3 \theta}\right)^{\frac{1}{4}}
$$

where the Lode angle $\theta$ is,

$$
\theta=\frac{1}{3} \sin ^{-1}\left(-\frac{3 \sqrt{3}}{2} \frac{\operatorname{det} \mathbf{s}}{\left(\frac{1}{2} \mathbf{s}: \mathbf{s}\right)^{3 / 2}}\right)
$$

The maximum value of $R(\theta)$ is $R=1$ when $\theta=-30^{\circ}$ (triaxial compression), and the minimum value is $R=\beta$ when $\theta=+30^{\circ}$ (triaxial extension). The parameter $\beta$ is referred to in this paper as 'triaxial extension factor'. The yield function is convex only when $\beta \geq 0.6$. A circular shape in the deviatoric plane is adopted for the plastic potential (i.e. no Lode angle dependency). This is consistent with 
experimental findings (e.g. Callisto and Calabresi, 1998; Prashant and Penumadu, 2004). The plastic potential function is therefore defined as,

$$
g=\sqrt{\mathbf{S}: \mathbf{S}}
$$

Three parameters are therefore required to calibrate each micro model, with $q_{\mathrm{uc}}$ and $\beta$ defining the plastic behaviour and $G_{0}$ defining the elastic response. The values of $q_{u c}$ and $\beta$ can be different for each micro model, but the same value of $G_{0}$ is applied to all of the micro models.

\subsection{Multi-surface extension}

For the complete model, a selected number of micro model instances are assembled in a parallel Iwan arrangement. All of the micro models are subjected to the same strain history, and the overall macro stress tensor, $\boldsymbol{\sigma}$, is calculated as a weighted average of the micro model stress tensors, $\boldsymbol{\sigma}_{\text {micro, }}$ (Equation (1)). For an infinitesimal increment of strain, $\delta \boldsymbol{\varepsilon}$, the resulting increment of the macro stress, $\delta \boldsymbol{\sigma}$, is,

$$
\delta \boldsymbol{\sigma}=\sum_{\mathrm{i}=1}^{n} w_{i} \mathbf{D}^{\mathrm{ep}} \delta \boldsymbol{\varepsilon}
$$

where,

$$
\mathbf{D}^{\mathrm{ep}}=\mathbf{D}^{\mathrm{e}}-\frac{\mathbf{D}^{\mathrm{e}}\left(\frac{\partial g}{\partial \boldsymbol{\sigma}_{\text {micro }}}\right)\left(\frac{\partial f}{\partial \boldsymbol{\sigma}_{\text {micro }}}\right)^{\mathrm{T}} \mathbf{D}^{\mathrm{e}}}{\left(\frac{\partial f}{\partial \boldsymbol{\sigma}_{\text {micro }}}\right)^{\mathrm{T}} \mathbf{D}^{\mathbf{e}}\left(\frac{\partial g}{\partial \boldsymbol{\sigma}_{\text {micro }}}\right)}
$$

and $\boldsymbol{\sigma}_{\text {micro }}$ is the micro stress tensor. The elastic stiffness matrix $\left(\mathbf{D}^{\mathrm{e}}\right)$ is based on the selected value of $\mathrm{G}_{0}$ and the prescribed value of Poisson's ratio ( 0.495 in the current implementation of the model).

In the finite element implementation of the model (described later), the response of the model to a finite strain increment $\Delta \varepsilon$ is determined by integrating Equation (8) using an explicit sub-stepping approach.

The PIMS model formulation described in the current paper is isotropic. The model does not include the influence of inherent anisotropy and it is recognised that this omission may be significant for some natural clays. However, the model can readily be extended to include the influence of inherent anisotropy by using a modified deviatoric stress tensor $\overline{\mathbf{s}}$ to define the yield and plastic potential functions for all of the micro models, following a similar approach to Prevost (1977), Grimstad et al. 
(2012) and Kouretzis et al. (2017). In this case, all occurrences of $\mathbf{s}$ in the definition of the yield surface and plastic potential of each micro model (Section 3.1) are replaced by $\overline{\mathbf{s}}$.

\subsection{Cyclic extension}

Within the basic parallel Iwan framework described above, an extension to account for cyclic loading is achieved by gradually reducing the weight of each micro model from the onset of cyclic loading by a cyclic degradation factor, $d(d \leq 1)$, so that the current weights are $d w_{i}$. This extension employs an 'overlay' approach, i.e. only the weights of the micro models are altered, with the underlying elasticperfectly-plastic micro models functioning as previously described.

The cyclic degradation overlay model is activated only if the current increment of loading is considered to be cyclic; therefore, an important component of the model is the method used to determine if cyclic loading is occurring. The current formulation makes this process relatively straightforward, with specific micro models being tracked to identify whether cyclic degradation should be applied for the current increment of strain. In the current model this is achieved by tracking the yield surfaces of three designated micro models, as described below.

i. One micro model is designated as the 'cyclic threshold surface' $\left(i=i_{\text {thr }}\right)$. Any cyclic loading that does not cause this model to yield does not cause degradation. The designation of the cyclic threshold surface index does not change during the calculation.

ii. The index of the 'largest currently active surface' $\left(i=i_{\text {lca }}\right)$ is stored and continually updated during the calculation. A micro model is deemed active if the micro stresses lie on the yield surface (i.e. plastic straining occurring).

iii. The index of a 'memory surface' $\left(i=i_{\text {mem }}\right)$ is stored and continually updated during the calculation. The value of $i_{\text {mem }}$ is the index of the largest micro model that has previously experienced plastic straining.

Cyclic degradation is activated for the current strain increment if $i_{\mathrm{thr}} \leq i_{\mathrm{lca}}<i_{\mathrm{mem}}$. To explain the approach, Fig. 4 shows a schematic of a strain-controlled load-unload-reload loop in a triaxial compression test, applied to a parallel Iwan model with four micro models employing von Mises yield surfaces. In this example, the cyclic threshold micro model is $i_{t h r}=1$. The initial loading stage (Fig. $4 a, b)$ causes no cyclic degradation since the memory surface and the largest currently active surface 
are the same throughout loading (i.e. $i_{\mathrm{lca}}=i_{\mathrm{mem}}$ ). At the end of initial loading, $i_{\mathrm{lca}}=i_{\mathrm{mem}}=3$. During unloading (Fig. 4c,d) and reloading (Fig. 4e,f), $i_{\text {mem }}$ is unchanged but $i_{\text {lca }}$ is updated, being set to zero as soon as unloading occurs. Therefore, for this example, cyclic degradation occurs during the unloading and reloading stages (except when the stresses lie inside the cyclic threshold surface).

Once the cyclic degradation model has been activated, degradation of stiffness and strength begins to occur; degradation is controlled by a set of cyclic degradation rules. The general approach adopted is consistent with empirical models derived from experimental studies, in which the rate of degradation has been found to depend on the cyclic strain amplitude, the OCR and the degree to which the backbone stress-strain curve has been mobilised prior to any load reversal (e.g. Vucetic and Dobry, 1988; Lefebvre and Pfendler, 1996; Andersen, 2015). Here the control parameter for cyclic degradation is the accumulated value of the von Mises equivalent strain, defined as,

$$
E_{q}=\left(\frac{2}{9}\left[\left(\varepsilon_{x}-\varepsilon_{y}\right)^{2}+\left(\varepsilon_{y}-\varepsilon_{z}\right)^{2}+\left(\varepsilon_{z}-\varepsilon_{x}\right)^{2}\right]+\frac{1}{3}\left[\gamma_{x y}^{2}+\gamma_{x z}^{2}+\gamma_{y z}^{2}\right]\right)^{1 / 2}
$$

When computing the updated stresses due to the $k^{\text {th }}$ increment of von Mises equivalent $\operatorname{strain}\left(\Delta E_{q, k}\right)$, the cyclic degradation factor $\left(d_{k}\right)$ for the current strain increment is determined as:

$$
d_{k}=\left(A \Delta E_{q, k}+E_{q}^{*}\right)^{-a}
$$

where $A$ is a parameter and $E_{q}{ }^{*}$ is:

$$
E_{q}^{*}=d_{k-1}-\frac{1}{a}
$$

where $d_{k-1}$ is the cyclic degradation factor for the previous strain increment. At the start of the analysis, the cyclic degradation factor is initialised as $d_{0}=1.0$ (i.e. no degradation), so that $E_{q}{ }^{*}$ also has an initial value of 1.0. This provides a straightforward practical approach, but it clearly ignores any von Mises equivalent strains that may have developed in in situ soil, due to prior geological processes, or in laboratory test samples, due to sample preparation procedures. The degradation rule employed in the PIMS model employs the accumulated total von Mises equivalent strain as the control parameter. An alternative approach would be to relate the degradation to the accumulated plastic strain. The current, empirical, approach is preferred, however, on the basis that it provides a more straightforward way of calibrating the model to laboratory test data.

The value of $a$ in Equations (11) and (12) is determined by the micro stress conditions in the 'outer' micro model (i.e. for $i=n$ ) as, 


$$
a=\frac{r}{\mathrm{OCR}^{c}}\left(\frac{q_{\max , n}}{q_{u c, n}}\right)^{b}
$$

where $b, c, r$ are parameters, $q_{u c, n}$ is the outer micro model's yield surface size parameter, and $q_{\max , n}$ is the maximum mobilised micro deviatoric stress value that has previously been experienced by the outer micro model of the quantity,

$$
q_{n}=\sqrt{\frac{3}{2} \mathbf{s}_{n}: \mathbf{s}_{n}}
$$

where $\mathbf{s}_{\boldsymbol{n}}$ is the deviatoric stress tensor for the outer micro model. This modelling approach means that the rate of degradation depends on the amplitude of the cyclic strain and also on the degree to which the backbone curve has been mobilised prior to unloading.

The exponent $c$ in Equation (13) allows the rate of cyclic degradation to depend on the initial overconsolidation ratio, OCR (e.g. Vucetic and Dobry, 1988; Yasuhara et al., 2003; Thian and Lee, 2017). In the examples presented later in this paper, however, this dependence on OCR is excluded by setting $c=0$. This aspect of the model is therefore not considered in the examples presented later.

Fig. 5 provides an illustration of the adopted cyclic degradation modelling approach, for an arbitrary parameter set. Three packets of two-way cyclic strain-controlled loading are applied, for triaxial test conditions, as shown in Fig. 5a. Each cycle is applied in four strain increments. The dashed lines in Fig. 5a indicate cases when cyclic degradation does not occur in the model (since in these cases $\left.i_{m e m}=l_{\text {lca }}\right)$; conversely, the solid lines indicate when cyclic degradation is active. The evolution of the degradation factor, $d$, with strain increment number, $k$, is shown in Fig. $5 \mathrm{~b}$. It can be seen that when the amplitude of cyclic loading changes (i.e. at increments 41 and 82 ) the degradation rate also changes due to the updated value of the exponent $a$ in Equation (11). The use of $E_{q}{ }^{*}$, (Equation (12), ensures that there is no sudden 'jump' in degradation factor when the cyclic strain amplitude changes.

The value of $d_{k}$ calculated from Equation (11) is applied equally to the weights of the micro models,

$$
w_{i, k}=d_{k} w_{i}
$$

As the weight $w_{i, k}$ of each micro model is reduced due to cyclic degradation, the overall sum of the weights reduces such that $\sum w_{i, k} \neq 1$. Conceptually it is considered that the degraded portion of the weight, $w_{d}=1.0-d_{k}$, is moved to a notional micro model with zero stiffness and strength (analogous to element breakage in the 1D model of Iwan and Cifuentes (1986)). 
The various components of the model (i.e. the dependence on cyclic amplitude, backbone mobilisation and OCR, and the inclusion of a cyclic threshold) allow established experimental trends to be captured.

The cyclic degradation component of the model, discussed above, will result in an accumulation of strain during a stress-controlled cyclic simulation; however, in its current form the model does not predict the accumulation of strain during cyclic loading without degradation (i.e. ratcheting type behaviour) at element level. Although this is a limitation of the model, it should be noted that purely ratcheting type behaviour with no stiffness degradation is not often observed in cyclic laboratory element tests in clay for a low number of cycles (e.g. Vucetic and Dobry, 1988; Okur and Ansal, 2007; Andersen, 2015; Wichtmann and Triantafyllidis, 2017) for which the model described in this paper has been developed.

\subsection{Implementation}

The PIMS model has been implemented as a user-defined soil model in the commercial finite element code Plaxis (Plaxis, 2017). The soil model was implemented as a dynamic link library (DLL), programmed in Fortran. The Fortran DLL routine receives information on the current micro stress states, $\boldsymbol{\sigma}_{\mathrm{micro}, k-1}$, the current model indices $i_{m e m, k-1}$ and $i_{l c a, k-1}$ and the overall strain increment, $\Delta \boldsymbol{\varepsilon}_{k-1}$. The model then delivers updated values of the micro stresses, $\boldsymbol{\sigma}_{\mathrm{micro}, k}$, and the corresponding macro stress, $\boldsymbol{\sigma}_{k}$ employing an explicit sub-stepping approach with automated error control, based on the recommendations presented by Sloan et al. (2001). Updated values of $i_{m e m, k}$ and $i_{l c a, k}$ are also returned.

The micro stresses need to be stored and tracked for each micro model, which results in a significant data storage requirement at each integration point in the analysis. For example, for a parallel Iwan model with $n=10$ micro models and a mesh consisting of tetrahedral elements with four integration points, 264 individual stress values per element (including micro stresses and the overall model macro stress) need to be stored, together with the current values of $i_{m e m}$ and $i_{l c a}$. Although this implies a high memory demand, it is somewhat offset by the fact that the micro model constitutive calculations are extremely simple and hence fast to compute. 


\section{CALIBRATION OF THE PIMS MODEL}

\subsection{Monotonic calibration}

To apply the model, the parameters for each micro model's yield surface $\left(q_{u c, i}, \beta_{i}\right)$ and the weights $\left(w_{i}\right)$ need to be calibrated, together with the overall small-strain elastic shear modulus $\left(G_{0}\right)$. This calibration is conducted in terms of normalised, dimensionless, variables as described below. The calibration process is illustrated for an example case in Fig. 6.

It is convenient to calibrate the model using data from isotropically consolidated undrained triaxial compression and extension tests. This calibration process requires data on $G_{0}$ determined, for example, from triaxial testing using local strain gauges or via separate bender element tests. The model is calibrated in terms of the normalised variables $\bar{\varepsilon}_{q}$ and $\bar{q}$ where,

$$
\bar{\varepsilon}_{q}=I_{r}^{*} \varepsilon_{q} ; \quad I_{r}^{*}=\frac{3 G_{0}}{2 s_{u c}} ; \quad \bar{q}=\frac{q}{q_{u c}}
$$

where $s_{u c}\left(=q_{u c} / 2\right)$ is the undrained shear strength in triaxial compression (determined from the triaxial test data). The response of the model can be conveniently represented by the normalised tangent stiffness $\bar{G}=G_{\mathrm{tan}} / G_{0}$, where $G_{\mathrm{tan}}$ is the tangent shear modulus. This normalisation approach has the desirable feature that the area beneath the $\left(\bar{\varepsilon}_{\mathrm{q}}, \bar{G}\right)$ curve is constrained to be equal to unity (i.e. $\left.\int_{0}^{\infty} \bar{G} d \bar{\varepsilon}_{\mathrm{q}}=1\right)$. On this basis, it is assumed that the normalised backbone curves $\bar{q}\left(\bar{\varepsilon}_{q}\right)$ and $\bar{G}\left(\bar{\varepsilon}_{q}\right)$ are a unique feature of any particular geotechnical unit identified in an overall ground model.

For implementation purposes, at a particular location in the geotechnical unit, calibrated values of $\beta_{i}$ and $w_{i}$ determined in this normalised space can be applied directly in the model. Appropriate values of the strength parameters $q_{u c, i}$ are determined by scaling the calibrated normalised values $\bar{q}_{u c, i}$ on the basis of the normalisation in Equation (15), employing the local (measured) value of $s_{u c}$. The elastic component of the model is specified directly using the local value of $G_{0}$. A comparable approach was adopted by Dong et al. (2015) to calibrate a multi-surface total stress model for Shanghai Clay.

The first step in the calibration process is to collect the available triaxial compression test data, for the particular geotechnical unit being modelled, on a single plot in $\left(\bar{\varepsilon}_{q}, \bar{q}\right)$ space (Fig. 6a). Next, the number, $n$, of micro models to be employed is selected ( $n=9$ in the Fig. 6 example). It is then necessary to select desired values of 'normalised yield strain', $\bar{\varepsilon}_{q c, i}$, corresponding to the values of 
normalised triaxial shear strain $\bar{\varepsilon}_{q}$ at which yielding of each micro model first occurs. The 'inner' micro model, $i=1$, corresponds to the boundary of elastic behaviour; the value of $\bar{\varepsilon}_{q c, 1}$ is therefore selected to define an appropriate strain limit on the small strain elastic behaviour implied by the model. The outer micro model $(i=n)$ is specified to have a normalised yield strain $\bar{\varepsilon}_{q c, n}$ that is sufficiently large for the limiting state $\bar{q}=1$ to have been reached in the test data. Values of the intermediate micro model normalised yield strains are then selected as required. (A logarithmic spacing along the $\bar{\varepsilon}_{q}$ axis is adopted in the Fig. 6 example). Additionally, if the cyclic overlay model is to be employed, a cyclic threshold surface $i=i_{t h r}$ needs to be specified at an appropriate value of $\bar{\varepsilon}_{q c, t h r}$ (see later). As a consequence of the adopted normalisation, the normalised micro model's triaxial compression shear strengths are determined straightforwardly by $\bar{q}_{u c, i}=\bar{\varepsilon}_{q c, i}$. Next, the triaxial compression data in $\left(\bar{\varepsilon}_{q}, \bar{q}\right)$ space are fitted with a series of linear segments, joining points corresponding to the previously-defined $\bar{\varepsilon}_{q c, i}$ data (Fig. 6a). As a consequence of the adopted normalisation, the first line segment (Fig. 6a, inset) has a gradient of 1.0 . Thereafter, the ordinate of the line segment's endpoints are chosen (by eye or numerical optimisation) to provide a fit with the triaxial data, as shown in Fig. $6 \mathrm{a}$. The resulting normalised stiffness backbone curve implied by the model is illustrated in Fig. $6 \mathrm{~b}$. The weights $w_{i}$ are determined from the steps in the backbone curve as,

$$
w_{i}=\Delta \bar{G}=\bar{G}_{i}-\bar{G}_{i+1}
$$

A typical normalised shear modulus backbone curve for triaxial compression implied by the model is depicted in Fig. 7a. The corresponding normalised backbone curve in triaxial extension, shown in Fig. $7 \mathrm{~b}$, is determined by employing the weights $w_{i}$ that were determined from the triaxial compression calibration, but with values of normalised yield strain given by $\bar{\varepsilon}_{\mathrm{qe}, \mathrm{i}}=\beta_{i} \bar{\varepsilon}_{\mathrm{qc}, \mathrm{i}}$ where $\beta_{i}$ are the triaxial extension factors for each micro model. Although it is possible to specify each micro model to have different values of $\beta_{i}$, in the current implementation all micro models have the same value, $\beta_{i}=\beta$. In this case, the normalised stiffness backbone curve for triaxial extension, illustrated in Fig. $7 \mathrm{~b}$, is simply a scaled version of the triaxial compression backbone curve (scale factor $\beta$ along the $\bar{\varepsilon}_{\mathrm{q}}$ axis). The area beneath the triaxial extension normalised shear modulus backbone curve is $\int_{0}^{\infty} \bar{G} d \bar{\varepsilon}_{\mathrm{q}}=\beta$.

\subsection{Cyclic calibration}

An appropriate value of $\bar{\varepsilon}_{q, t h r}$ (needed to specify the strength of the cyclic threshold micro model, $i=i_{t h r}$ ) needs to be selected. This can be determined experimentally, by conducting low amplitude cyclic laboratory tests (e.g. Jardine, 1992). 
The parameters $A, r, b$ are conveniently calibrated using strain-controlled two-way cyclic tests, employing a similar approach to Vucetic and Dobry (1988). Values of degradation factor, $d$ are determined from the test data as $d=G_{s e c, N} / G_{s e c, 1}$ (see Fig. 1). By conducting tests at different strain amplitudes, the influence of the accumulated deviatoric strain $\left(\sum \Delta E_{q}\right)$ on $d$ can be examined and the parameters $A, r, b$ determined.

Although, ideally, the model is calibrated using data from cyclic triaxial tests, (because in this case the stress conditions are fully defined), cyclic undrained direct simple shear (UDSScyc) tests are typically preferred in geotechnical practice. This is because a smaller volume of soil is required, so the sample preparation process is more likely to provide a reasonably consistent set of undisturbed samples. In this case, stress-controlled tests (in which the cyclic strain amplitude evolves with each cycle) and strain-controlled tests should ideally both be performed, at varying cyclic stress amplitudes, to calibrate the model and verify its performance.

\subsection{Model initialisation}

Initialisation of isotropic in situ stress conditions (i.e. $K_{0}=1$ ) is performed by setting the initial micro stress tensor in each model directly equal to the in situ total stress state (i.e. $\sigma_{\text {micro, } i}=\boldsymbol{\sigma}$ ). Therefore, when $K_{0}=1$ the initial stress state is at the centre of each micro model in the deviatoric plane (i.e. $q=0)$.

For non-isotropic initial in situ stress conditions (i.e. $K_{0} \neq 1$ ) a mobilised deviatoric stress is applied within the model. To achieve this, first the required initial deviatoric stress is applied based on the in situ stress conditions. Subsequently, along the same strain path a load-unload increment, which is equal to the elastic threshold strain, is applied. The applied load-unload increment of strain, $\Delta \varepsilon$, is set equal to the strain on the inner micro model (i.e. $\varepsilon_{1}$ ). The rationale for applying the small load-unload strain increment is to ensure that the initial stress state within each micro model does not lie on the yield surface and the initial micro deviatoric stress of the inner micro model is equal to zero. This then ensures that the initial response predicted by the model is equal to the elastic stiffness until the deviatoric strain increment, $\Delta E_{q}$, causes plastic straining to occur in the inner micro model. 


\section{APPLICATION OF THE PIMS MODEL}

\subsection{Overview of application examples}

This section describes the calibration of the PIMS model to monotonic and cyclic laboratory test data for two overconsolidated clays, accompanied by 3D FEA of monopile foundations subjected to monotonic and cyclic lateral loading.

One of these calibrations is conducted on samples of Bolders Bank clay, from sites in the North Sea, based on previous triaxial test data obtained from routine offshore site investigations conducted by Fugro. Index properties are listed in Table 1. Due to limitations in the available data, this calibration consists of monotonic loading parameters only.

To demonstrate the cyclic loading capabilities of the PIMS model, a second calibration is presented, for an overconsolidated clay, based on samples acquired and tested by Fugro during a routine offshore site investigation in the Belgian Sector of the southern North Sea. The calibration samples were all extracted from the same geotechnical clay unit, termed Unit A. The index properties of this unit are also listed in Table 1.

These data sets include of both monotonic and cyclic DSS tests; it was therefore possible to use these data to calibrate the cyclic parameters, as well as the underlying elasto-plastic parameters, in the PIMS model.

\subsection{Analysis of monopile embedded in Bolders Bank clay}

\subsubsection{Calibration of PIMS model for Bolders Bank clay}

Triaxial compression tests were conducted on Bolders Bank samples that had been recovered during routine offshore geotechnical investigations (conducted by Fugro) at several sites in the southern North Sea. A range of different values of $K_{o}$ were employed in the initial consolidation process employed in the triaxial tests. The OCR of the samples ranged from 2 to 7 .

The Bolders Bank formation is also the main geotechnical unit at the Cowden test site, where laterally loaded pile tests were conducted during the PISA research project (Byrne et al., 2019). Triaxial test data from the Cowden site (Zdravković et al., 2019) were found to be broadly consistent with the Fugro data set employed to calibrate the PIMS model. On the basis of this observation, several of the 
PISA pile tests were analysed using the calibrated PIMS model and the computed results compared with the field data (Byrne et al., 2019).

Fig. 8 illustrates normalised data from ten triaxial compression tests on undisturbed samples from the Bolders Bank formation. These data were selected from the Fugro data set for cases where the consolidation process in the triaxial tests employed a $K_{0}$ value close to 1.0. For each sample, a bender element test was performed prior to shearing to determine $G_{0}$ (required for the normalisation). An average axial strain rate of approximately $0.5 \%$ per hour was applied during the shearing stage. The data in Fig. 8 were used to calibrate a 12-surface PIMS model using the procedure described in Section 4.1; the resulting backbone curve is shown in Fig. 8. Based on a limited number of triaxial extension tests, the triaxial extension factor was set to $\beta=0.7$. The final calibration parameters are listed in Table 2.

\subsubsection{Single element simulations}

Simulations of several individual triaxial tests on Bolders Bank clay that were not included in the calibration process are shown in Fig. 9. Three of these cases (indicated 'Fugro data set') were consolidated using values of $K_{0}$ that departed from 1.0. In these cases, the simulations were conducted by applying appropriate axial and radial stresses to represent these initial $K_{0}$ conditions, using the approach discussed in Section 4.3, prior to modelling the shearing stage of the test. Also shown in Fig. 9 are separate data from a triaxial test conducted on a sample of clay till from the Cowden PISA test site (Zdravković et al., 2019) together with an equivalent simulation conducted using the current model calibration. The excellent agreement between the calibrated model and these test data provide an indication of the robustness of the calibration process. It is particularly noteworthy that the calibrated model is able to reproduce the triaxial test data obtained from the Cowden clay sample.

\subsubsection{Monotonic lateral loading of a monopile}

3D FEA of three monotonically-loaded pile tests at Cowden from the PISA research project (Byrne et al., 2019) have been conducted using the calibrated PIMS model. The pile load tests were carried out in a series of increments under displacement control at relatively slow constant displacement rates, separated by periods of maintained load in which creep and consolidation were observed (further details are provided in Byrne et al., 2019). The pile configurations that have been considered are 
specified in Table 3. The strain rate used to calibrate the model was considered appropriate for the loading rate employed in the PISA tests.

In the finite element model the soil domain was discretised using approximately 30,000 10-noded tetrahedral elements, exploiting symmetry as shown in the mesh in Fig. 10. The pile was modelled using 6-noded plate elements, with 12-noded zero-thickness interface elements on the external pile wall. The steel pile was modelled as a linear elastic material with $E=210 \mathrm{GPa}$ and $v=0.3$. The interface elements used an elasto-plastic Tresca model, with the elastic stiffness set to $10^{5} \mathrm{kN} / \mathrm{m}^{3}$ based on recommendations by Zdravković et al. (2019). Axial pile load testing performed by Lehane and Jardine (1994) at the Cowden test site found that the interface shear strength varied from 0.57 to 0.82 times the measured local undrained shear strength of the soil in triaxial compression; therefore, an interface shear strength of $0.7 s_{u c}$ was adopted in the current work. A zero-tension cutoff was prescribed for the interface elements to allow gapping to occur at the pile-soil interface. The lateral boundaries were $25 \mathrm{~m}$ from the centre of the pile for all cases. Fig. 11 shows the profiles of $s_{u c}$ and $G_{0}$ that were adopted for the analysis. The saturated bulk unit weight, $\gamma_{\mathrm{sat}}$, was taken as $21.19 \mathrm{kN} / \mathrm{m}^{3}$ for all analyses. These profiles are based on site-specific laboratory and in situ data reported by Zdravković et al. (2019).

Comparisons of the computed load-displacement responses with the measured pile load test data are shown in Fig. 12a (for the overall behaviour) and Fig. 12b (for the initial, small displacement, response). There is good agreement between the measured and computed responses; this provides an encouraging demonstration of the predictive capability of the PIMS model.

\subsection{Monopile embedded in overconsolidated clay (Unit A)}

\subsubsection{Calibration of PIMS model for overconsolidated clay (Unit A)}

A single undisturbed core sample from Unit A was sub-sampled for the UDSS test program. Symmetrical two-way cyclic loading with either a constant cyclic shear strain amplitude $\left(\gamma_{c y c}\right)$ or a constant cyclic shear stress amplitude $\left(\tau_{c y c}\right)$ was applied to each specimen. The tests are specified in Tables 4 and 5.

The monotonic stress-strain backbone curve was first calibrated directly to UDSS1, using a 12-surface PIMS model. A triaxial extension factor of $\beta=0.7$ was adopted. Calibration of the model was 
achieved by conducting simulations of UDSS1 and adjusting the weights, $w_{i}$, by eye to obtain a reasonable match between the data and the model. To simulate the test, the model was initialised for isotropic conditions (see Section 4.3). A shear stress was then applied, with zero lateral and vertical strain, to mimic the conditions in the UDSS test.

To calibrate for cyclic loading, it is necessary to consider the strain rate dependency of the soil. Viscous rate dependency of clays has been investigated experimentally by many authors, including Sheehan et al. (1996) and Torisu et al. (2012). The measured undrained shear strength is typically found to be adequately represented, for the range of strain rates considered in the current work, by a power function of the strain rate. To illustrate the cyclic performance of the model, a correction was applied to the undrained shear strength $s_{u c}$ to simulate a viscous rate dependency. This was done by applying a rate correction factor, $F_{\text {rate }}$, to the shear strength values, where,

$$
F_{\text {rate }}=\left(\frac{\dot{\varepsilon_{\mathrm{q}}}}{\dot{\varepsilon}_{\mathrm{q}, \text { ref }}}\right)^{h}
$$

where $\dot{\varepsilon}_{q, \text { ref }}$ is the strain rate used to calibrate the reference backbone curve (i.e. $3 \%$ per hour). On the basis of the available data, a value of $h=0.043$ was adopted.

\subsubsection{Single element simulations}

The strain rate correction method described above assumed a constant strain rate. It is noted, however, that the cyclic tests employed a sinusoidal variation of the prescribed strains/stresses. This means that the strain rate varies during the cycling; a single representative strain rate, however, needs to be selected for the current modelling approach. A representative value of $\dot{\varepsilon}_{\mathrm{q}}=7000 \%$ per hour was employed for the current analysis; this is based on the average strain rate applied during the first quarter cycle of a test, for tests UDSScyc2 and UDDScyc4 (i.e. corresponding to the highest and lowest strain rates applied in the testing). This strain rate correction approach is considered sufficient, as even relatively large variations in the strain rates applied in the cyclic tests cause only minor variations in the strain rate correction factor, when related to the reference strain rate of $3 \%$ per hour using the proposed power model. Fig. 13 compares the measured and simulated monotonic responses in various tests, with the strain rate correction applied in the simulations. The generally good agreement between the simulations and measured data, for different loading rates, highlights the suitability of the adopted rate correction method. The final calibration parameters for the cyclic rate corrected backbone curve are listed in Table 2 . 
The cyclic parameters were calibrated using a process, similar to the one outlined in Section 4.2, in which values of $A, r, b$ are selected to provide a match between the model and the data. The final calibration values are listed in Table 6 .

The performance of the model in simulating four separate UDSScyc tests is illustrated in Fig. 14. For 100 simulated cycles, the response of the calibrated model shows good agreement with the measured data in both strain-controlled tests (UDSScyc-1 and UDSScyc-2) and stress-controlled tests (UDSScyc-3 and UDSScyc-4). This is promising, since it indicates that the model is capable of capturing a reasonable response for conditions when the stress or strain amplitude varies over a number of cycles. The applied rate correction method also appears adequate as the first quarter cycle response in each cyclic test simulation shows reasonable agreement with the test data.

Although the cyclic single element simulation results presented are felt to be encouraging, further work is required to compare the performance of the model with laboratory data for a wider range of cyclic stress conditions (e.g. considering cases where the mean shear stresses are non-zero).

\subsubsection{Cyclic lateral loading of a monopile}

The calibrated cyclic model was used to perform 3D FEA of an example offshore monopile foundation subjected to a storm-type history of cyclic lateral loading. By employing the PIMS model in this application, it is possible to capture the stress history and the variable cyclic degradation across the soil domain. A uniform soil profile was used, taking $\gamma_{\mathrm{sat}}=20 \mathrm{kN} / \mathrm{m}^{3}$ and adopting the cyclic ratecorrected backbone curve (labelled 'UDSScyc Simulation' in Fig. 13), for which $G_{0}=116 \mathrm{MPa}$ and $s_{u c}=252 \mathrm{kPa}$.

The soil domain was discretised using 27,456 10-noded tetrahedral elements, with the lateral boundaries of the mesh situated $60 \mathrm{~m}$ from the centre of the pile. The pile and the pile-soil interface were modelled as specified in Section 5.1.3. Details of the pile geometry and loading conditions for this analysis are given in Table 7. One-way lateral cyclic loading was applied to the pile in two loadcontrolled packets to mimic storm loading conditions. Load packet 1 consisted of 70 cycles with a peak lateral load of $20 \mathrm{MN}$, followed by load packet 2 which consisted of 16 cycles with a peak load of $28 \mathrm{MN}$. In both cases the trough load was zero. 
Fig. 15a shows the load-displacement response of the pile at seabed level. Within each cyclic loading packet there is a gradual accumulation of lateral displacement, though the rate of accumulation decreases with each cycle. Several centrifuge model testing studies investigating cyclic lateral loading of monopiles in clay (e.g. Zhang et al., 2010; Hong et al., 2017; Yu et al., 2018) have also shown a degradation in the cyclic lateral stiffness, together with a gradual accumulation of lateral displacement. It is interesting to note that the overall stiffness response of the pile does not degrade significantly within each cyclic load packet. For example, within load packet 2 (i.e. cycles 70 to 86) the FEA predicts a $3 \%$ reduction in the secant unload-reload stiffness (Fig. 15a) even though significantly higher levels of localised degradation occur in the soil over the same period (see next paragraph). Therefore, at a global level, ratcheting-type behaviour of pile is observed with little stiffness reduction. The computed accumulated displacements are shown more clearly in Fig. 15b, which presents a plot of the accumulated displacement versus number of cycles.

Fig. 16 shows the evolution of the cyclic degradation factor, $d$, in the soil around the pile. During each packet of cyclic loading there is progressive degradation ( $d$ reduces from its initial value of 1.0) and this gradually propagates to a larger volume of soil as the cyclic loading continues. It is clear that a complex spatial and temporal evolution of the cyclic degradation factor occurs. Fig. 16 shows that as the cyclic loading proceeds, the region of degradation also propagates down the pile, with the degradation at the pile toe becoming more significant as the rigid pile rotates; this is in contrast to a flexible pile, for which more localised cyclic degradation near the seabed would be expected. It is therefore likely that the propagation of cyclic degradation in the soil, and hence the overall cyclic response of the pile, will be significantly affected by the L/D ratio of the pile being considered. 


\section{CONCLUSIONS}

A practical multi-surface total stress model - PIMS - is proposed to represent the monotonic and cyclic loading behaviour of clay, for cases where the soil is undrained. This model, together with associated finite element implementation and calibration procedures, has been developed specifically to facilitate robust geotechnical calculations for practical applications relating to offshore foundations.

The basic parallel Iwan framework that is adopted for the PIMS model is a well-established constitutive modelling approach, although there are few documented applications of this framework in geotechnical engineering. Although previous researchers have explored the application of series forms of the Iwan framework to represent soil behaviour, the current paper demonstrates that the parallel form is a particularly attractive option for practical geotechnical calculations. The parallel Iwan framework is relatively straightforward to explain (e.g. to clients, regulators and insurers) to implement (in finite element codes) and to calibrate (using routine site investigation procedures).

The basic Iwan framework employed in the PIMS model is capable of being extended, as required, to account for additional aspects of soil behaviour. An extension to the model, incorporating cyclic loading effects, is described in the current paper. A separate extension for inherent soil anisotropy has also been developed, although this extension is outside the current scope. Further extensions are considered feasible, for example to incorporate rate effects explicitly in the model, rather than employing the simple rate correction approach that is adopted in the current work. It would also be possible to incorporate different forms of cyclic response, for example employing separate models for the stiffness and strength degradation components of behaviour.

An important feature of the PIMS model, from a geotechnical practitioners' perspective, is that it can be calibrated using laboratory test procedures that are routinely employed in geotechnical site investigation practice. Calibration of the basic parallel Iwan framework is demonstrated in the current paper using data from standard triaxial compression and extension tests (with bender elements) and direct simple shear tests. A calibration of the cyclic overlay model is also demonstrated, although the calibration procedure in this case is less systematic; it consists essentially of adjusting the model parameters until a satisfactory fit is obtained with data from cyclic triaxial and/or direct simple shear tests. This study has focused on calibration of the model using conventional laboratory tests only (triaxial test and direct simple shear test); further work should be performed to investigate the 
performance of the PIMS model when compared to laboratory test data performed under more complex stress paths (such as employing the hollow cylinder apparatus to impose rotation of the principal stresses during the test).

The Iwan framework has the considerable advantage that backbone curves of arbitrary shape can be represented, by appropriate choices of the number of micro models, the micro model parameters and the associated weights. However, the current modelling approach is unable to represent soil behaviour for cases where a peak, and post peak softening, occurs in the stress-strain backbone curve. In its current form, therefore, the model is unsuitable for heavily overconsolidated clay for which softening behaviour may be relevant.

The example 3D finite element analyses of laterally loaded monopiles presented in the paper demonstrate the practical application of the PIMS model. The analysis of three of the PISA test piles, although limited to monotonic behaviour, provides an indication of the predictive capabilities of the proposed modelling and calibration framework. This is particularly the case as the PIMS model was calibrated for this example using test data on Bolders Bank clay (considered to be the same geotechnical unit as the glacial clay till encountered at the Cowden site employed for the PISA tests) that relate to offshore locations at some distance from the PISA test site. The separate example presented in the paper, in which a monopile is subjected to cyclic lateral loading, is a hypothetical case and so field data on foundation performance are not available for comparison purposes. Nevertheless, this example analysis does demonstrate the robustness and feasibility of the model implementation. Additionally, the computed results are broadly consistent with expected forms of behaviour.

\section{ACKNOWLEDGEMENTS}

This work was supported by grant EP/L016303/1 for Cranfield University and the University of Oxford, Centre for Doctoral Training in Renewable Energy Marine Structures - REMS (http://www.remscdt.ac.uk/) from the UK Engineering and Physical Sciences Research Council (EPSRC). 


\section{REFERENCES}

Andersen KH. 2015. Cyclic soil parameters for offshore foundation design. In 3rd International Symposium on Frontiers in Offshore Geotechnics, Oslo, Norway, (1):p5-84.

Byrne BW, McAdam RA, Burd HJ, Beuckelaers WJA, Gavin K, Houlsby GT, Igoe D, Jardine RJ, Martin CM, Muir Wood A, Potts DM, Skov Gretlund J, Taborda DMG, Zdravković L. 2019. Monotonic lateral loaded pile testing in a stiff glacial clay till at Cowden. Géotechnique (in press).

Callisto L, Calabresi G. 1998. Mechanical behaviour of a natural soft clay. Géotechnique, 48(4):p495513.

Chiang DY, Beck JL. 1994. A new class of distributed-element models for cyclic plasticity-I theory and application. International Journal of solids and structures, 31(4):p469-484.

Clayton CRI. 2011. Stiffness at small strain: research and practice. Géotechnique, 61(1):p5-37.

Corciulo S, Zanoli O, Pisano F. 2017. Supporting the Engineering Analysis of Offshore Wind Turbines Through Advanced Soil-Structure 3D Modelling. In ASME 2017 36th International Conference on Ocean, Offshore and Arctic Engineering (pp. V009T10A015-V009T10A015). American Society of Mechanical Engineers.

Dafalias YF, Manzari MT, Papadimitriou AG. 2006. SANICLAY: Simple anisotropic clay plasticity model. International Journal for Numerical and Analytical Methods in Geomechanics, 30(12):p1231-1257.

Dong YP, Burd HJ, Houlsby GT. 2015. Finite-element analysis of a deep excavation case history. Géotechnique, 66(1):p1-15.

Einav I, Collins IF. 2008. A thermomechanical framework of plasticity based on probabilistic micromechanics. Journal of Mechanics of Materials and Structures, 3(5):p867-892.

Elgamal A, Yang Z, Parra E, Ragheb A. 2003. Modelling of cyclic mobility in saturated cohesionless soils. International Journal of Plasticity, 19(6):p883-905.

Grimstad G, Andresen L, Jostad H. 2012. NGI-ADP: Anisotropic shear strength model for clay. International Journal for Numerical and Analytical Methods in Geomechanics, 36:p483-497.

Grimstad G, Rønningen J, Nøst H. 2014. Use of IWAN models for modelling anisotropic and cyclic behavior of clays. In $8^{\text {th }}$ European Conference on Numerical Methods in Geotechnical Engineering, Delft, Netherlands, (1):p49-55.

Gu C, Wang J, Cai Y, Guo L. 2014. Influence of cyclic loading history on small strain shear modulus of saturated clays. Soil Dynamics and Earthquake Engineering, 66:p1-12.

Haiderali AE, Nakashima M, Madabhushi SPG. 2015. Cyclic lateral loading of monopiles for offshore wind turbines. In 3rd International Symposium on Frontiers in Offshore Geotechnics, Oslo, Norway, (1):p711-716

Hardin BO, Black WL. 1968. Vibration modulus of normally consolidated clay. J Soil Mech Found Div ASCE, 94(2):p353-369.

Hong Y, He B, Wang LZ, Wang Z, Ng, CWW, Mašín D. 2017. Cyclic lateral response and failure mechanisms of semi-rigid pile in soft clay: centrifuge tests and numerical modelling. Canadian Geotechnical Journal, 54(6):p806-824.

Houlsby, GT. 1999 A model for the variable stiffness of undrained clay. Proc. Int. Symp. on PreFailure Deformation Characteristics of Soils, Turin, (1):p443-450.

Huang M, Liu Y. 2015. Axial capacity degradation of single piles in soft clay under cyclic loading. Soils and Foundations, 55(2):p315-328.

Hyde AFL, Ward SJ. 1986. The effect of cyclic loading on the undrained shear strength of a silty clay. Marine Georesources and Geotechnology, 6(3):p299-314.

Idriss IM, Dobry R, Sing RD. 1978. Nonlinear behaviour of soft clays during cyclic loading. Journal of Geotechnical Engineering, 104(12):p1427-1447.

Iwan WD, Cifuentes AO. 1986. A model for system identification of degrading structures. Earthquake Engineering and Structural Dynamics, 14:p877-890.

Iwan WD. 1966. A distributed-element model for hysteresis and its steady-state dynamic response. Journal of Applied Mechanics, 33(4):p893-900.

Iwan WD. 1967. On a class of models for the yielding behavior of continuous and composite systems. Journal of Applied Mechanics, 34(3):p612-617.

Kouretzis G, Jubert P, Krabbenhøft K. 2017. Interpretation of vane shear tests for geotechnical stability calculations. Canadian Geotechnical Journal, 54(12):p1775-1780.

Ladd CC. 1991. Stability evaluation during staged construction. Journal of Geotechnical Engineering, 117(4):p540-615.

Lefebvre G, Pfendler P. 1996. Strain rate and preshear effects in cyclic resistance of soft clay. Journal of Geotechnical Engineering, 122(1):p21-26.

Lehane BM, and Jardine RJ. 1994. Displacement pile behaviour in glacial clay. Canadian Geotechnical Journal, 31(1):p79-90. 
Mortezaie A, Vucetic M. 2016. Threshold shear strains for cyclic degradation and cyclic pore water pressure generation in two clays. Journal of Geotechnical and Geoenvironmental Engineering, 142(5):p1-14.

Mroz Z. 1967. On the description of anisotropic work hardening. Journal of the Mechanics and Physics of Solids, 15(3):p163-175.

Nishimura S, Minh NA, Jardine RJ. 2007. Shear strength anisotropy of natural London Clay. Géotechnique, 57(1):p49-62.

Okur DV, Ansal A. 2007. Stiffness degradation of natural fine grained soils during cyclic loading. Soil Dynamics and Earthquake Engineering, 27(9):p843-854.

Plaxis. 2017. Plaxis 3D, version 2017.1

Prashant A, Penumadu D. 2004. Effect of intermediate principal stress on overconsolidated kaolin clay. Journal of Geotechnical and Geoenvironmental Engineering, 130(3):p284-292.

Prévost JH. 1977. Mathematical modelling of monotonic and cyclic undrained clay behaviour. International Journal for Numerical and Analytical Methods in Geomechanics, 1(2):p195-216.

Sheahan TC, Ladd CC, Germaine JT. 1996. Rate-dependent undrained shear behaviour of saturated clay. Journal of Geotechnical Engineering, 122(2):p99-108.

Sheng D, Sloan SW, Yu HS. 2000. Aspects of finite element implementation of critical state models. Computational mechanics, 26(2):p185-196.

Sivasithamparam N. 2012. Development and implementation of advanced soft soil models in finite elements. PhD Thesis, University of Strathclyde. Glasgow, UK.

Skau KS. 2018. Modelling of skirted foundations for offshore wind turbines. PhD Thesis, Norwegian University of Science and Technology.

Sloan SW, Abbo AJ, Sheng D. 2001. Refined explicit integration of elastoplastic models with automatic error control. Engineering Computations,18(1/2):p121-194.

Stallebrass SE, Taylor RN, 1997. The development and evaluation of a constitutive model for the prediction of ground movements in overconsolidated clay. Géotechnique, 47(2):p235-253.

Thian SY, Lee CY. 2017. Cyclic stress-controlled tests on offshore clay. Journal of Rock Mechanics and Geotechnical Engineering, 9(2):p376-381.

Torisu SS, Pereira JM, De Gennaro V, Delage P, Puech A. 2012. Strain-rate effects in deep marine clays from the Gulf of Guinea. Géotechnique, 62(9):p767-775.

Vardanega PJ, Bolton MD. 2013. Stiffness of clays and silts: normalizing shear modulus and shear strain. Journal of Geotechnical and Geoenvironmental Engineering, 139(9):p1575-1589.

Vucetic M, Dobry R. 1988. Degradation of marine clays under cyclic loading. Journal of Geotechnical Engineering, 11(2):p133-149.

Vucetic M. 1994. Cyclic threshold shear strains in soils. Journal of Geotechnical Engineering, 120(12):p2208-2228.

Whittle AJ, Kavvadas MJ. 1994. Formulation of MIT-E3 constitutive model for overconsolidated clays. Journal of Geotechnical Engineering, 120(1):p173-198.

Wichtmann T, Triantafyllidis T. 2017. Monotonic and cyclic tests on kaolin: a database for the development, calibration and verification of constitutive models for cohesive soils with focus on cyclic loading. Acta Geotechnica, 13(5):p1103-1128.

Yasuhara K, Murakami S, Song BW, Yokokawa S, Hyde AF. 2003. Post-cyclic degradation of strength and stiffness for low plasticity silt. Journal of Geotechnical and Geoenvironmental Engineering, 129(8):p756-769.

Yu J, Leung CF, Huang M, Goh SC. 2018. Application of T-bar in numerical simulations of a monopile subjected to lateral cyclic load. Marine Georesources and Geotechnology, 36(6):p643-651.

Zdravković L, Taborda DMG, Potts DM, Abadias D, Burd HJ, Byrne BW, Gavin K, Houlsby GT, Jardine RJ, Martin CM, McAdam RA, Ushev E. 2019. Finite element modelling of laterally loaded piles in a stiff glacial clay till at Cowden. Géotechnique (in press).

Zhang C, White D, Randolph M. 2010. Centrifuge modelling of the cyclic lateral response of a rigid pile in soft clay. Journal of Geotechnical and Geoenvironmental Engineering, 137(7):p717-729. 


\section{TABLES}

Table 1: Index properties for Bolders Bank and Unit A clay

Index Bolders Bank Unit A

\begin{tabular}{ccc}
\hline$w$ & $12 \%-25 \%$ & $25 \%-45 \%$ \\
$I_{P}$ & $15 \%-25 \%$ & $15 \%-35 \%$ \\
$\rho_{s}$ & $2.67 \mathrm{Mg} / \mathrm{m}^{3}-2.70 \mathrm{Mg} / \mathrm{m}^{3}$ & $2.66 \mathrm{Mg} / \mathrm{m}^{3}-2.73 \mathrm{Mg} / \mathrm{m}^{3}$ \\
$\gamma_{s a t}$ & $20.0 \mathrm{kN} / \mathrm{m}^{3}-22.5 \mathrm{kN} / \mathrm{m}^{3}$ & $17.5 \mathrm{kN} / \mathrm{m}^{3}-20.0 \mathrm{kN} / \mathrm{m}^{3}$ \\
\hline Notes: $w$ & s water content, $I_{P}=$ plasticity index, $\rho_{s}=$ density of solid particles, $\gamma_{\text {sat }}=$ saturated unit weight \\
\hline
\end{tabular}

Table 2: PIMS calibration parameters for Bolders Bank and Unit A

\begin{tabular}{clllllllllllll}
\hline $\begin{array}{c}\text { Soil } \\
\text { Unit }\end{array}$ & & $\mathbf{i = 1}$ & $\mathbf{i}=\mathbf{2}$ & $\mathbf{i}=\mathbf{3}$ & $\mathbf{i}=\mathbf{4}$ & $\mathbf{i}=\mathbf{5}$ & $\mathbf{i}=\mathbf{6}$ & $\mathbf{i}=\mathbf{7}$ & $\mathbf{i}=\mathbf{8}$ & $\mathbf{i}=\mathbf{9}$ & $\mathbf{i}=\mathbf{1 0}$ & $\mathbf{i}=\mathbf{1 1}$ & $\mathbf{i}=\mathbf{1 2}$ \\
\hline Bolders & $\bar{\varepsilon}_{q c, i}$ & 0.0075 & 0.0225 & 0.0750 & 0.2250 & 4.0000 & 10.0000 & 16.8800 & 33.7500 & 56.2500 & 90.0000 & 135.0000 & 180.0000 \\
Bank & $w$ & 0.06333 & 0.18486 & 0.27928 & 0.43330 & 0.01923 & 0.00547 & 0.00624 & 0.00208 & 0.00267 & 0.00200 & 0.00089 & 0.00066 \\
& $\bar{\varepsilon}_{q c, i}$ & 0.0066 & 0.0660 & 0.1980 & 0.6600 & 1.2000 & 3.3000 & 6.7500 & 15.0000 & 27.0000 & 34.5000 & 42.0000 & 52.5000 \\
Unit A & $w$ & 0.43771 & 0.33502 & 0.07576 & 0.05892 & 0.04497 & 0.00414 & 0.01802 & 0.00962 & 0.00517 & 0.00533 & 0.00152 & 0.00382 \\
\hline
\end{tabular}

Notes: $\bar{\varepsilon}_{q c}=$ micro model normalised yield strain in triaxial compression, $w=$ micro model weight, $n=$ micro model number, $\beta=0.7$ used for all micro models

Table 3: Analysed pile geometries from the PISA tests at Cowden (Byrne et al., 2019)

\begin{tabular}{lccccc}
\hline Pile Ref. & $\begin{array}{c}\mathbf{D} \\
(\mathbf{m})\end{array}$ & $\begin{array}{c}\mathbf{L} \\
(\mathbf{m})\end{array}$ & L/D & $\begin{array}{c}\mathbf{t} \\
(\mathbf{m m})\end{array}$ & $\begin{array}{c}\mathbf{h} \\
(\mathbf{m})\end{array}$ \\
\hline CM2 & 0.762 & 2.24 & 2.94 & 10 & 10 \\
CM9 & 0.762 & 4.98 & 5.22 & 11 & 10 \\
CM3 & 0.762 & 7.59 & 9.96 & 25 & 10 \\
\hline
\end{tabular}

Notes: $\mathrm{D}=$ pile diameter, $\mathrm{L}=$ pile embeded length, $\mathrm{t}=$ pile wall thickness, $\mathrm{h}=$ lever arm of horizontal load

Table 4: Cyclic undrained direct simple shear (UDSScyc) tests on Clay Unit A

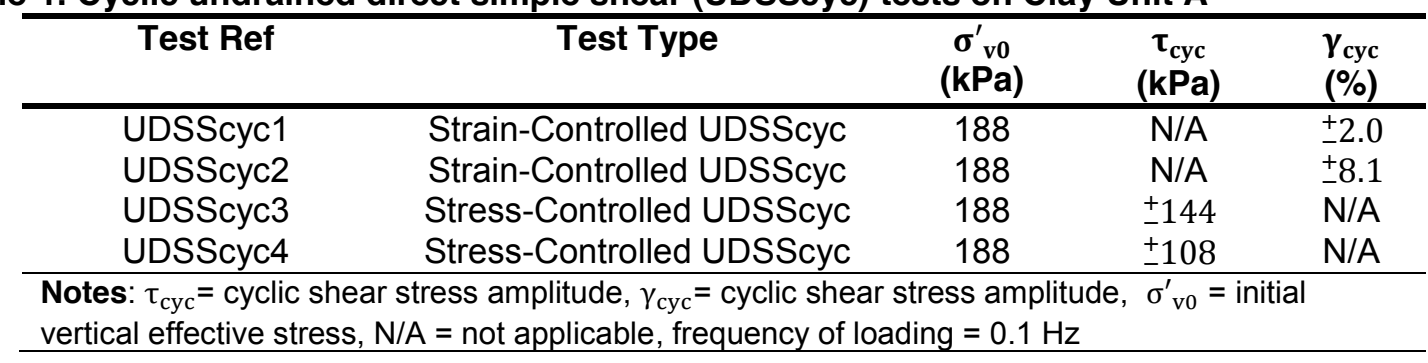


Table 5: Monotonic undrained direct simple shear (UDSS) tests on Clay Unit A

\begin{tabular}{ccc}
\hline Test Ref & $\begin{array}{c}\boldsymbol{\sigma}_{\mathbf{v 0}}^{\prime} \\
(\mathbf{k P a})\end{array}$ & $\begin{array}{c}\text { Loading Rate } \\
\text { (\%/hour) }\end{array}$ \\
\hline UDSS1 & 188 & 3 \\
UDSS2 & 188 & 300 \\
\hline Notes: $\sigma_{\text {v0 }}^{\prime}=$ initial vertical effective stress \\
\hline
\end{tabular}

Table 6: Clay Unit A cyclic degradation overlay model parameters

\begin{tabular}{cc}
\hline Parameter & Value \\
\hline $\mathrm{A}$ & 2.82 \\
$\mathrm{~b}$ & 0.43 \\
$\mathrm{r}$ & 0.6 \\
$\mathrm{c}$ & 0 \\
$\bar{\varepsilon}_{q, \text { thr }}$ & 0.066 \\
\hline
\end{tabular}

Table 7: Analysed pile geometry for Clay Unit A

\begin{tabular}{|c|c|c|c|c|}
\hline $\begin{array}{c}D \\
(m)\end{array}$ & $\begin{array}{c}\mathrm{L} \\
(\mathrm{m})\end{array}$ & L/D & $\begin{array}{c}t \\
(\mathbf{m m})\end{array}$ & $\begin{array}{c}\mathrm{h} \\
(\mathrm{m})\end{array}$ \\
\hline 7.5 & 25 & 3.33 & 75 & 25 \\
\hline
\end{tabular}




\section{FIGURES}

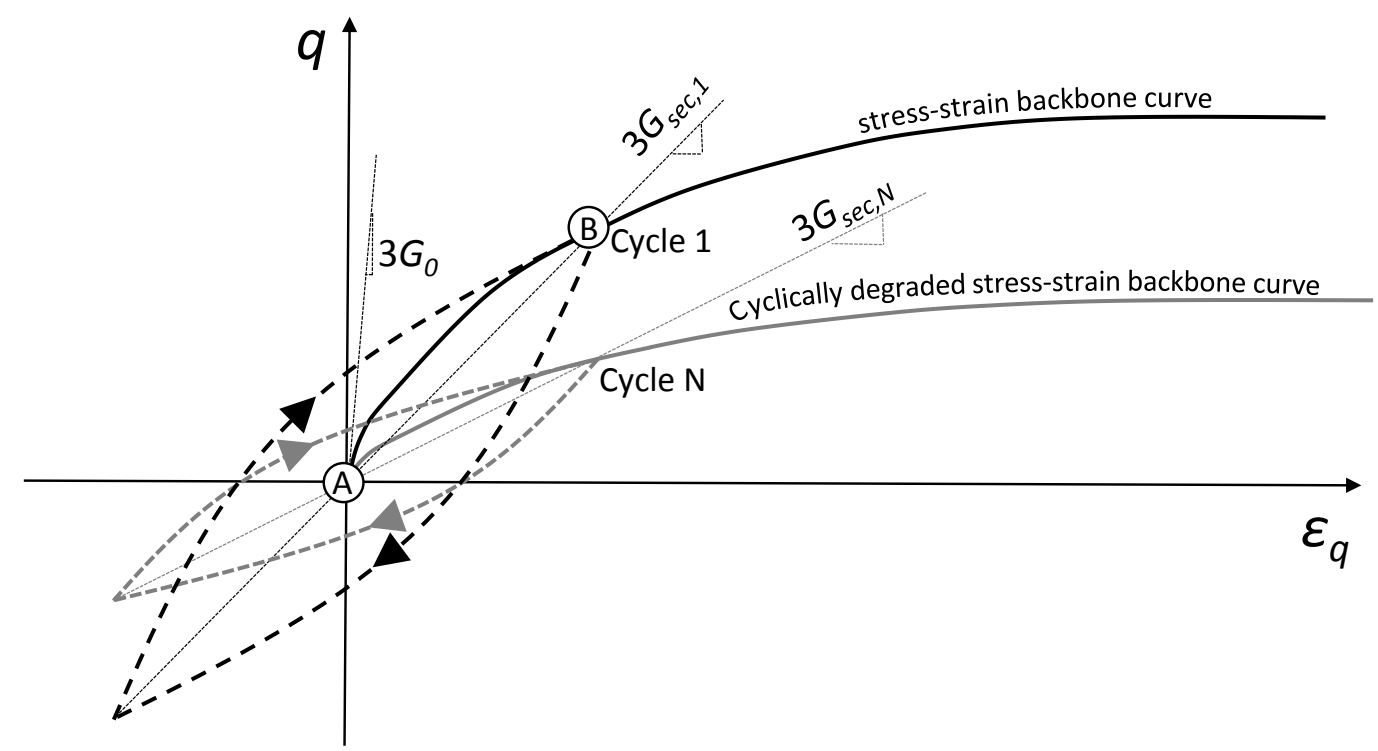

Figure 1: Schematic of stress-strain backbone curves before and after symmetrical two-way strain controlled cyclic loading, for triaxial conditions

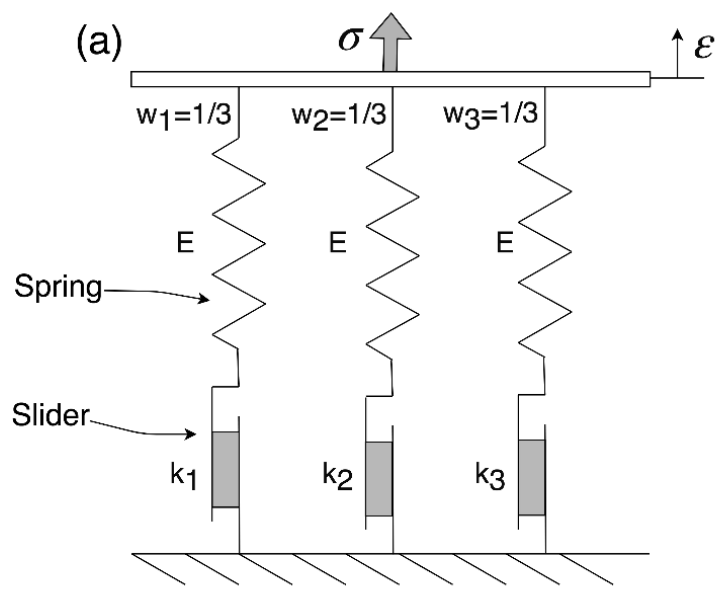

(b)

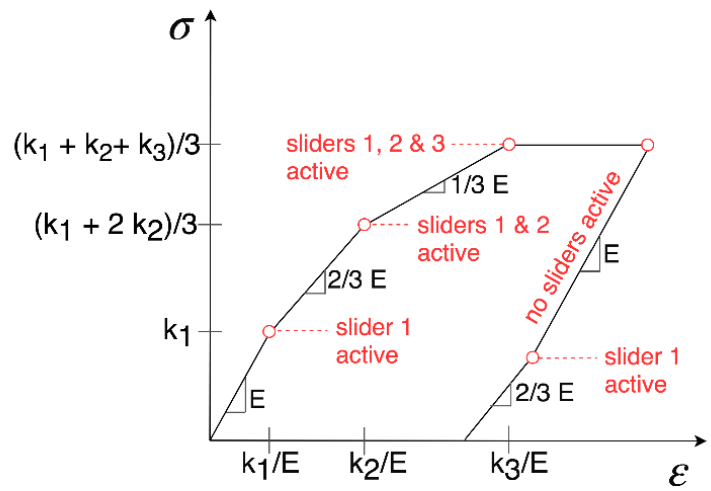

Figure 2: 1D parallel Iwan model consisting of three spring-slider elements with example stress-strain load-unload response 
(a)

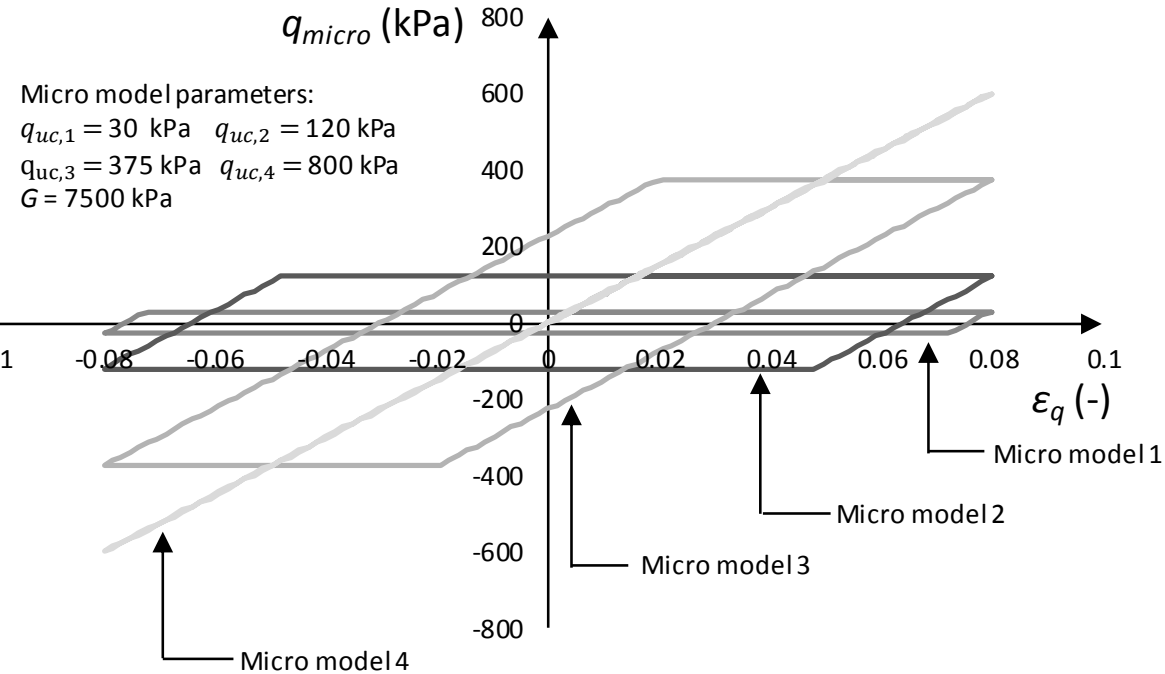

(b)

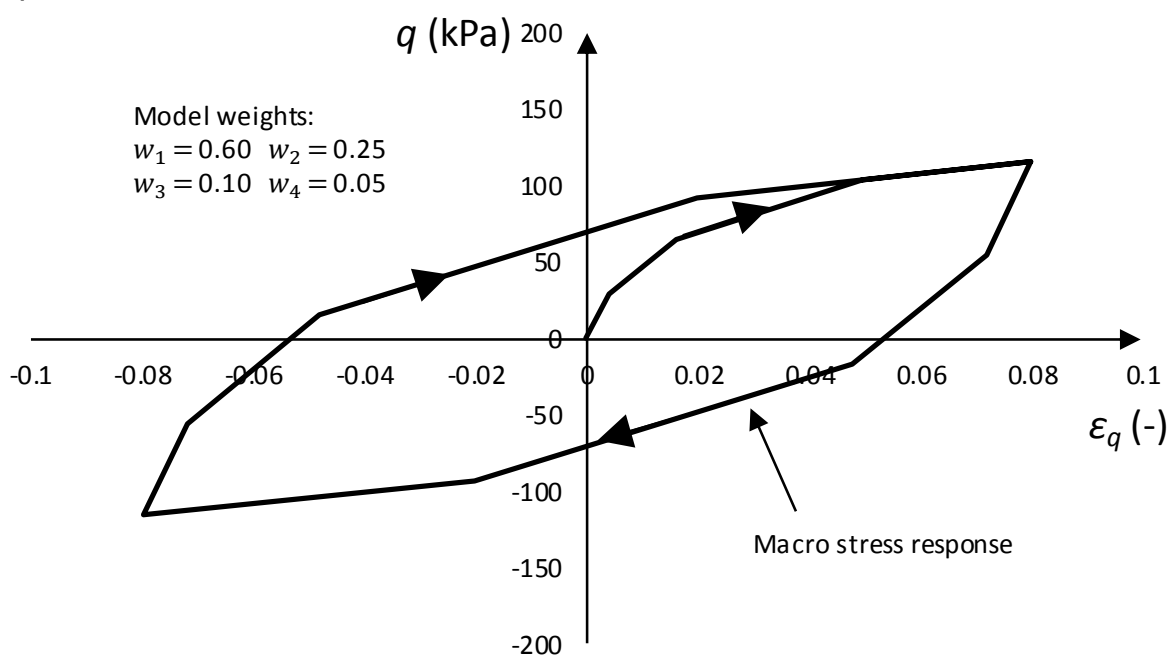

Figure 3: Example micro and macro stress-strain response for a parallel lwan model consisting of four micro von Mises models in a symmetrical two-way strain-controlled cyclic triaxial test 


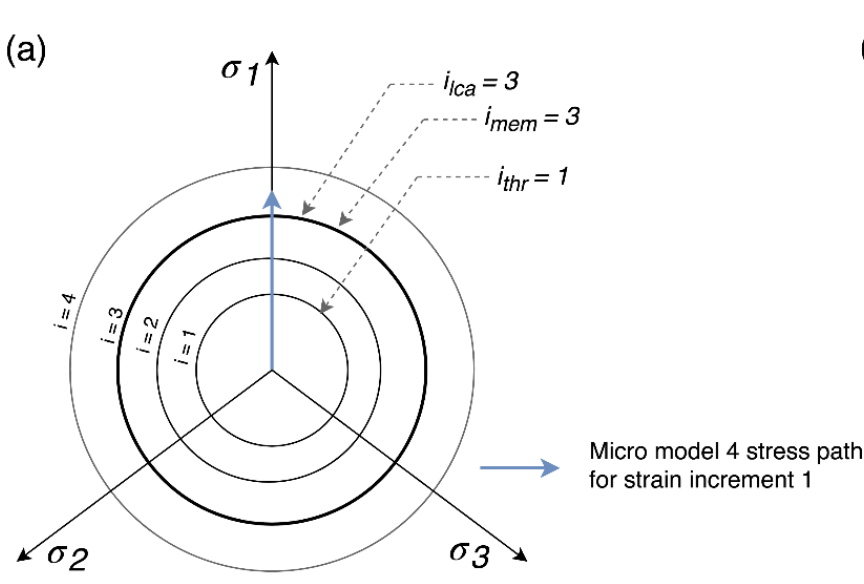

(b)

Global stress-strain response without degradation overlay model

(c)

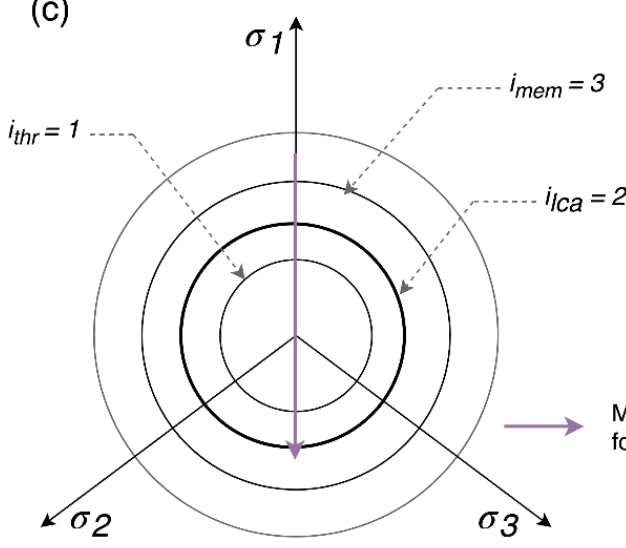

Micro model 4 stress path for strain increment 2

(e)

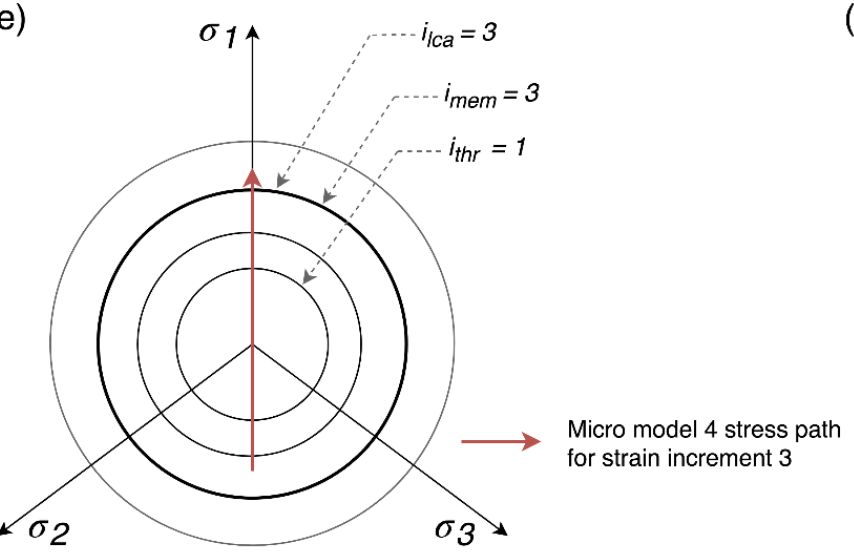

(d)

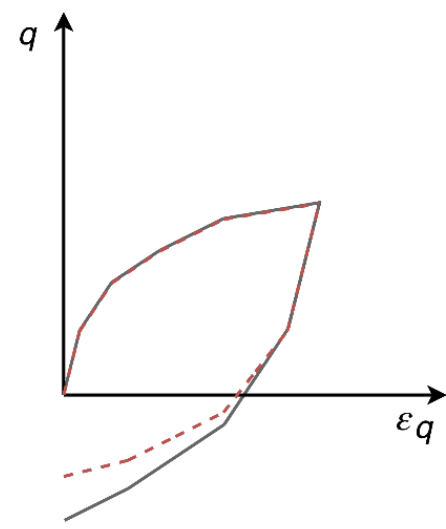

(f)

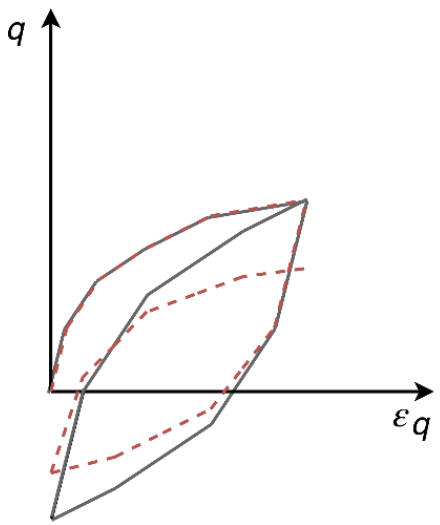

Figure 4: Schematic of the cyclic degradation overlay model with four von Mises micro models for a triaxial load-unload-reload test showing the stress path for micro model $i=4$ and the overall macro stress-strain response with, and without, cyclic degradation applied 

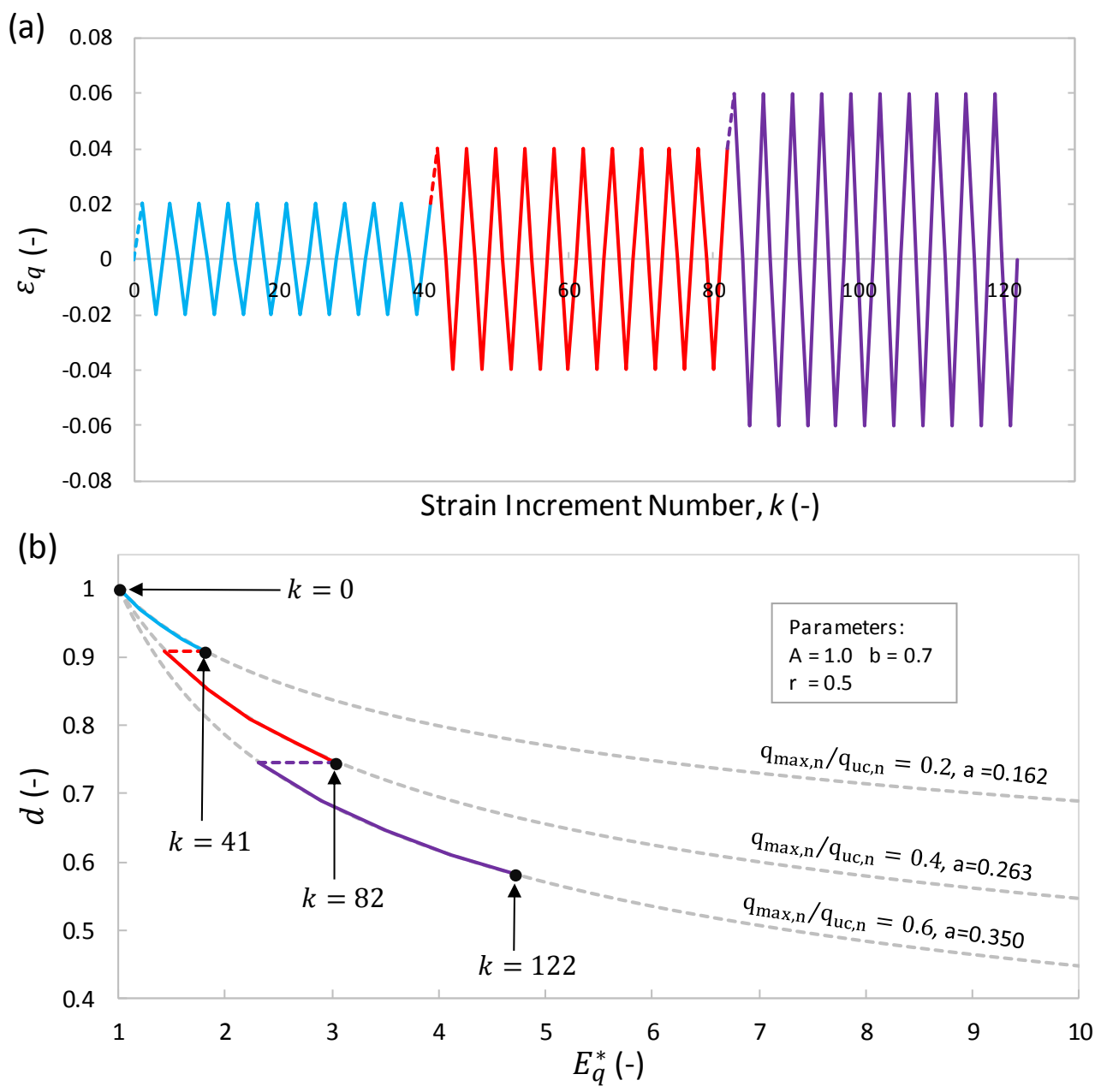

Figure 5: Example cyclic degradation factor calculation for a symmetrical two-way straincontrolled cyclic triaxial test with varying amplitudes using the PIMS model 


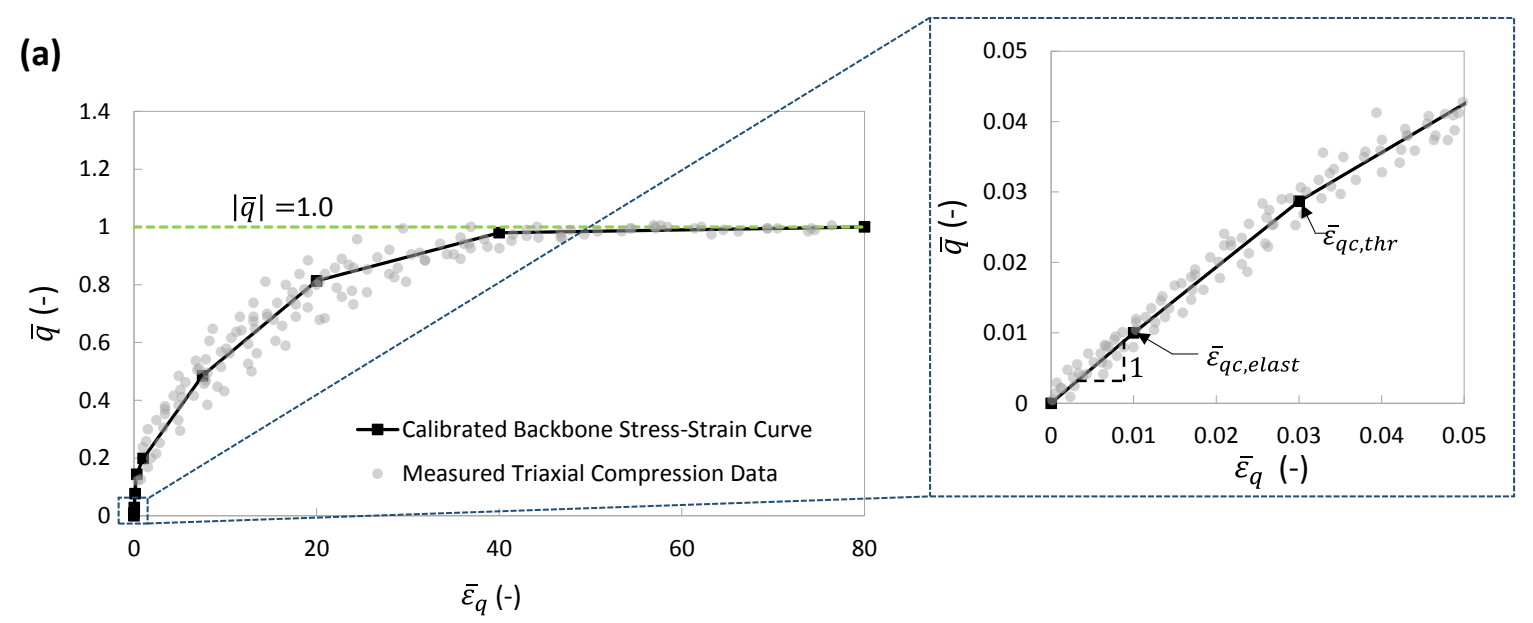

(b)

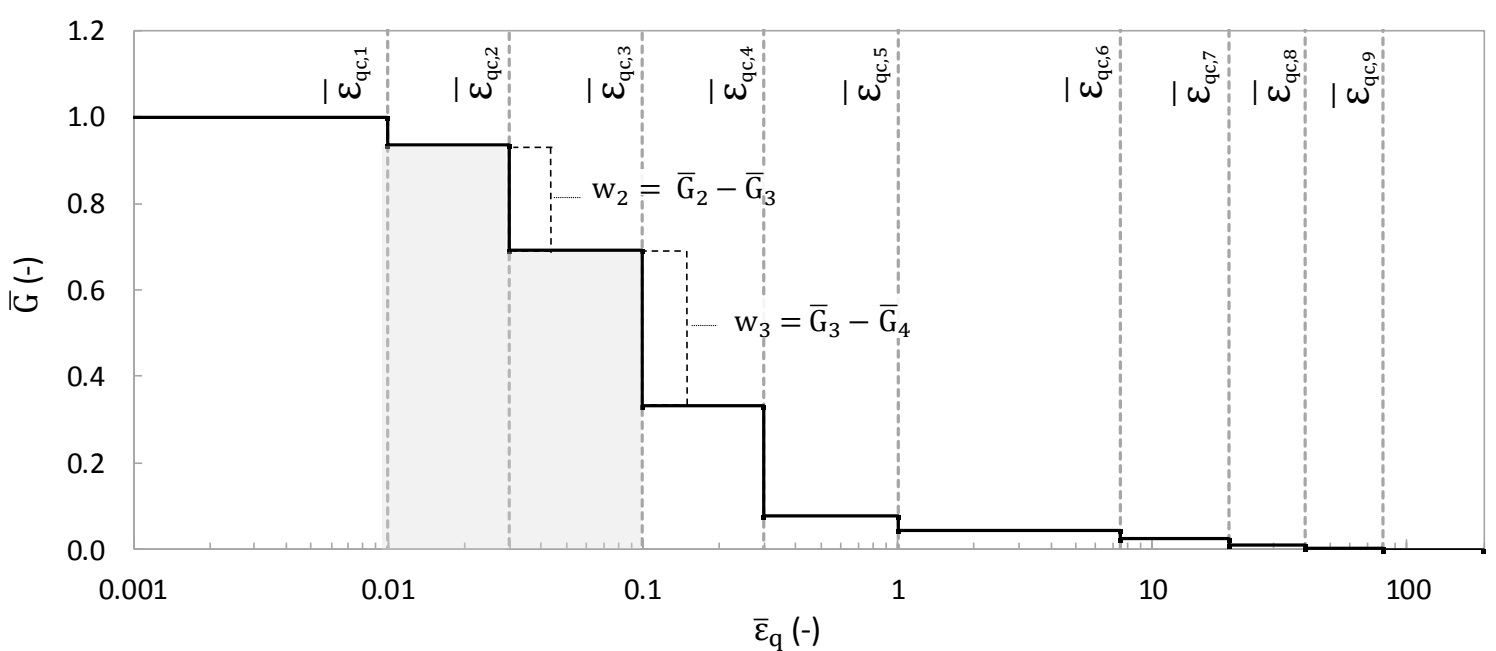

Figure 6: (a) Triaxial compression data and example best fit backbone curve stress-strain curve with small strain zoom view and with derivation of PIMS micro model parameters from (b) normalised stiffness degradation curve

(a)

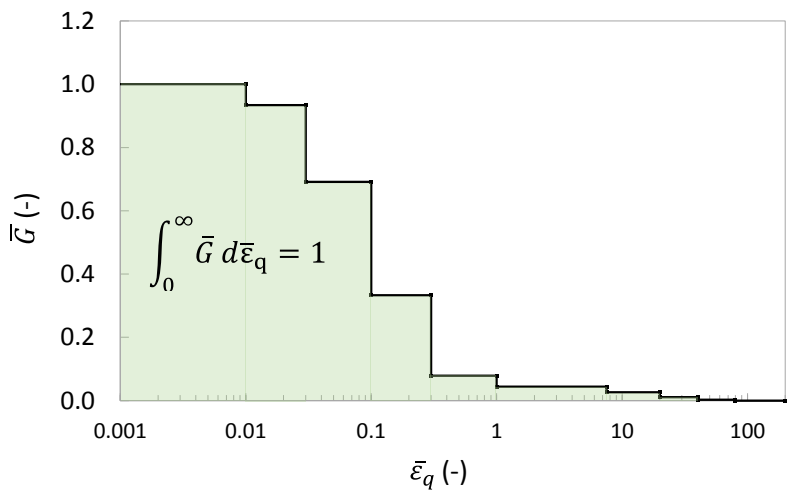

(b)

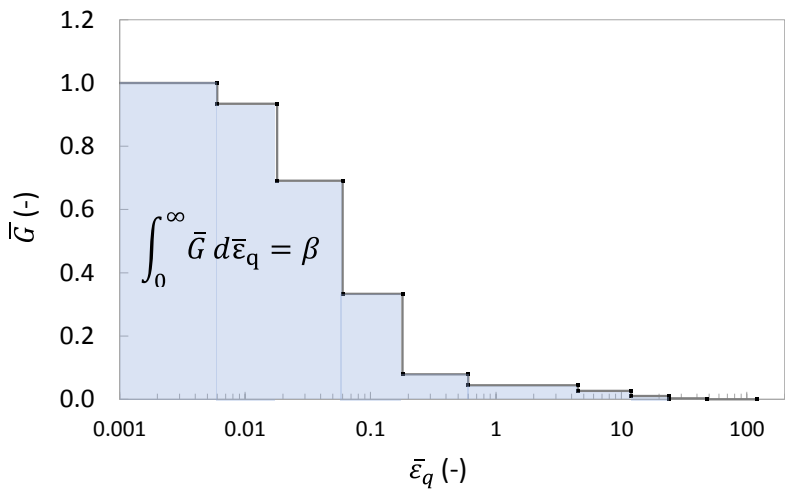

Figure 7: Example normalised tangent stiffness backbone curves in triaxial compression and extension with $\beta=0.6$ 


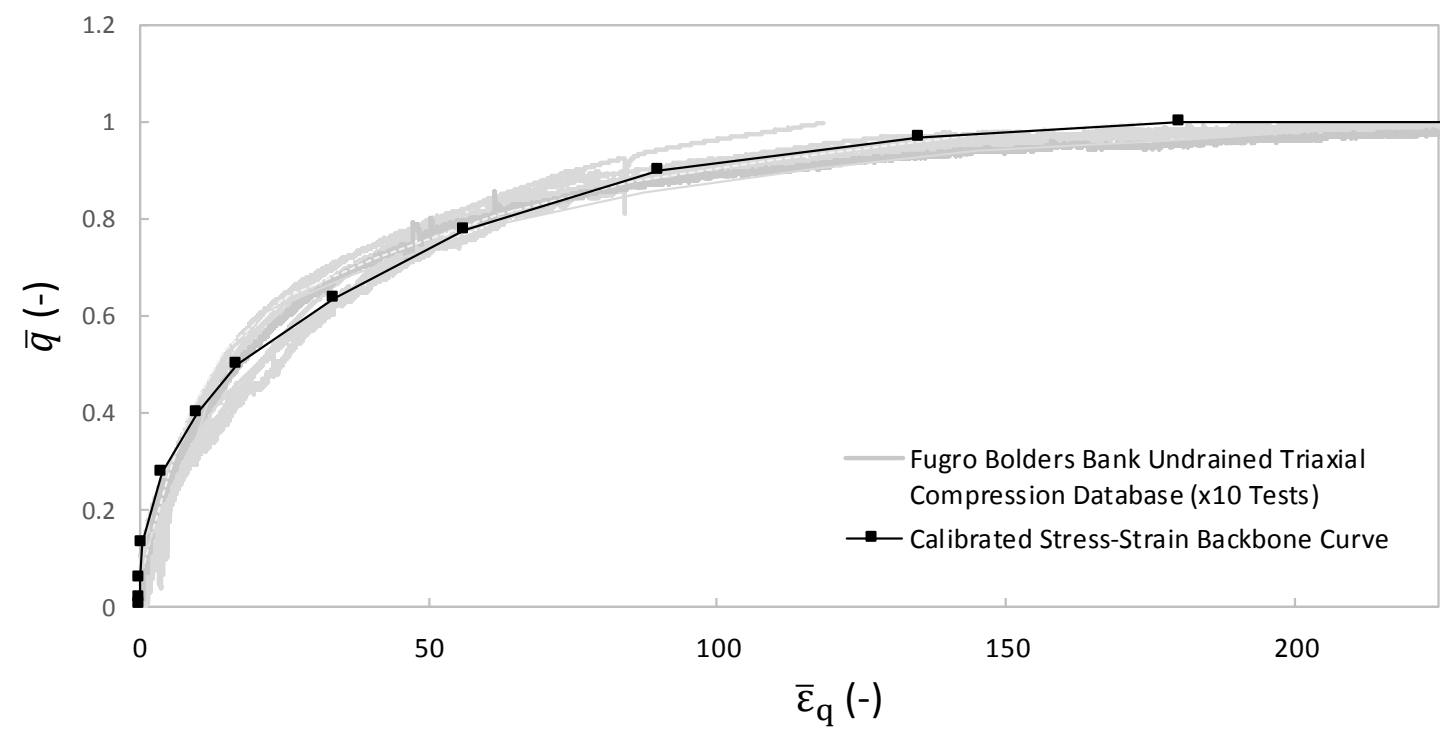

Figure 8: Bolders Bank clay undrained triaxial compression monotonic test data with double normalisation applied and the calibrated stress-strain backbone curve

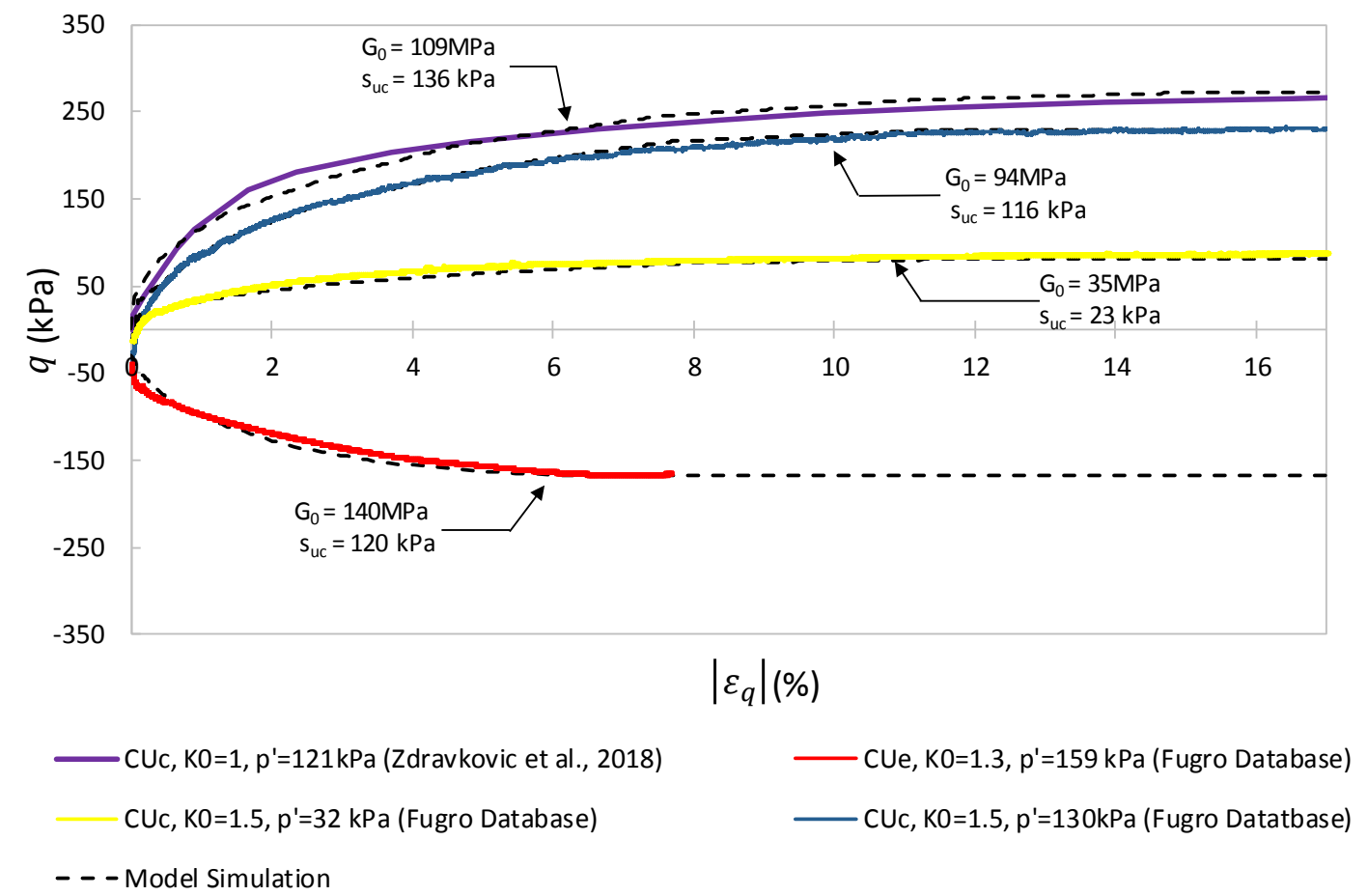

Figure 9: PIMS model simulations compared to triaxial laboratory test data from the Bolders Bank clay unit 


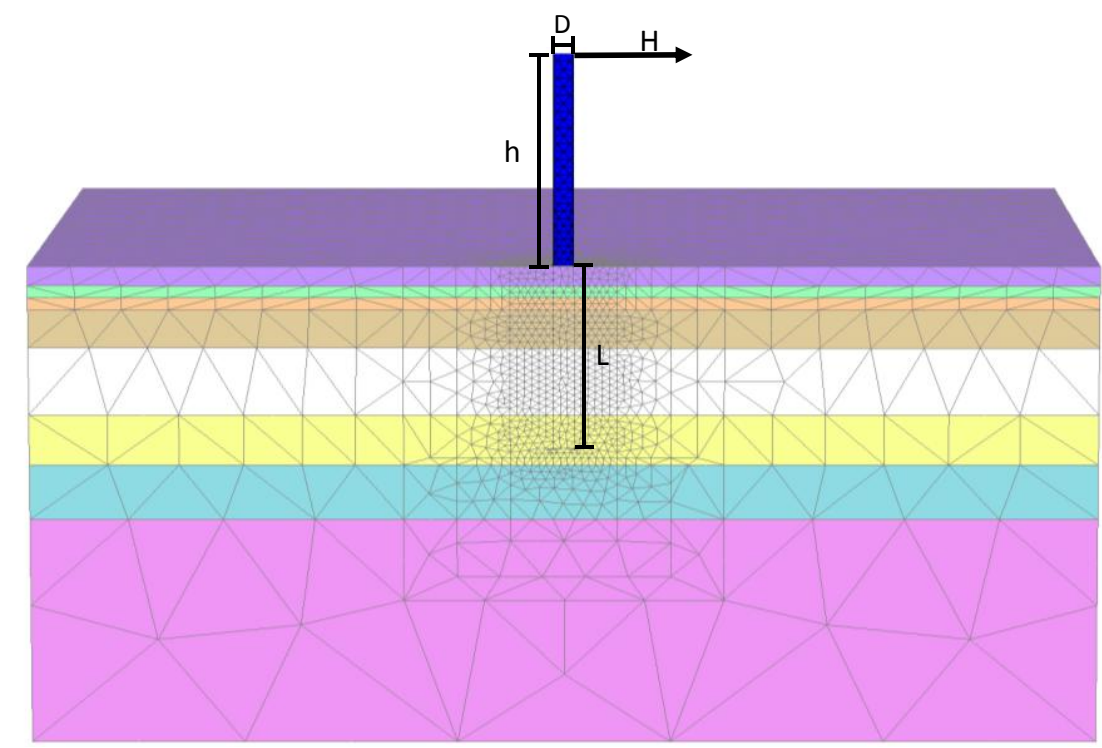

Figure 10: Example 3D mesh for pile with diameter of $0.762 \mathrm{~m}$ and an embedment length of 7.59 m (pile CM3 from PISA pile load tests)

(a)

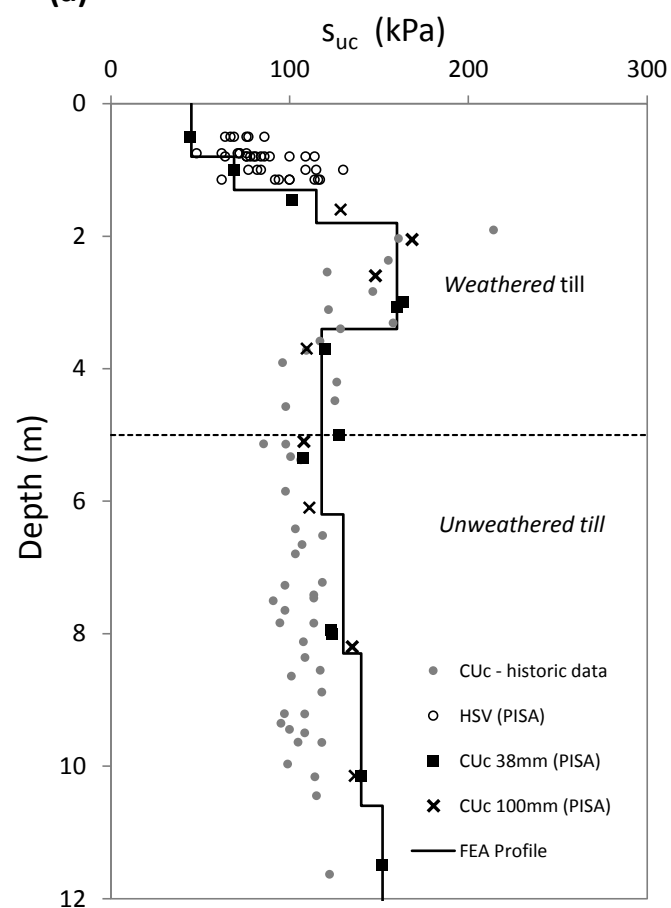

(b)

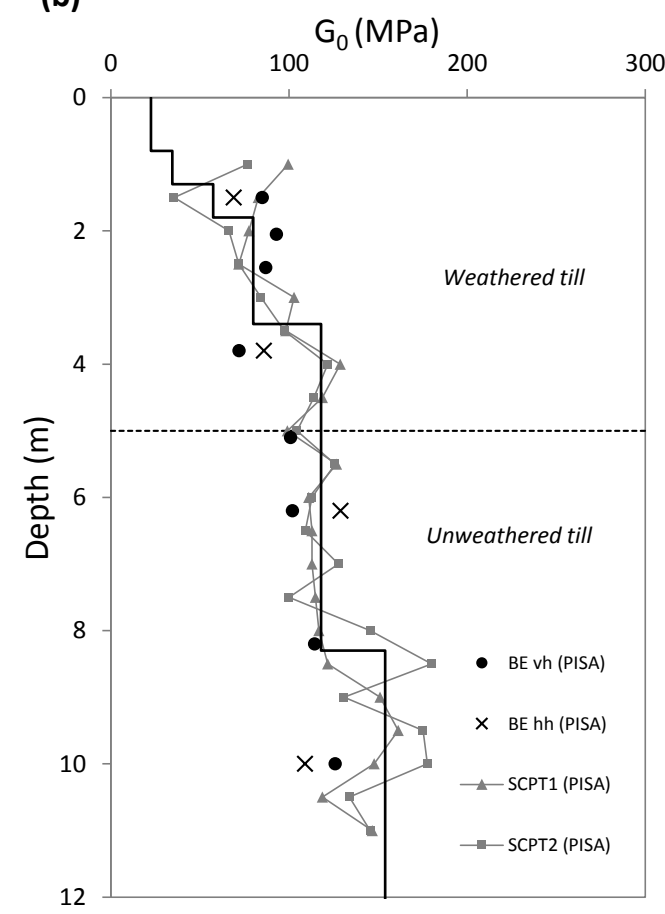

Figure 11: Undrained shear strength and small strain shear modulus data from the Cowden PISA pile tests site along with interpreted profiles used for finite element analyses; HSV = hand shear vane, $\mathrm{BE}=$ bender element, $\mathrm{SCPT}=$ seismic cone penetration test (test data from Zdravković et al., 2019) 
(a)

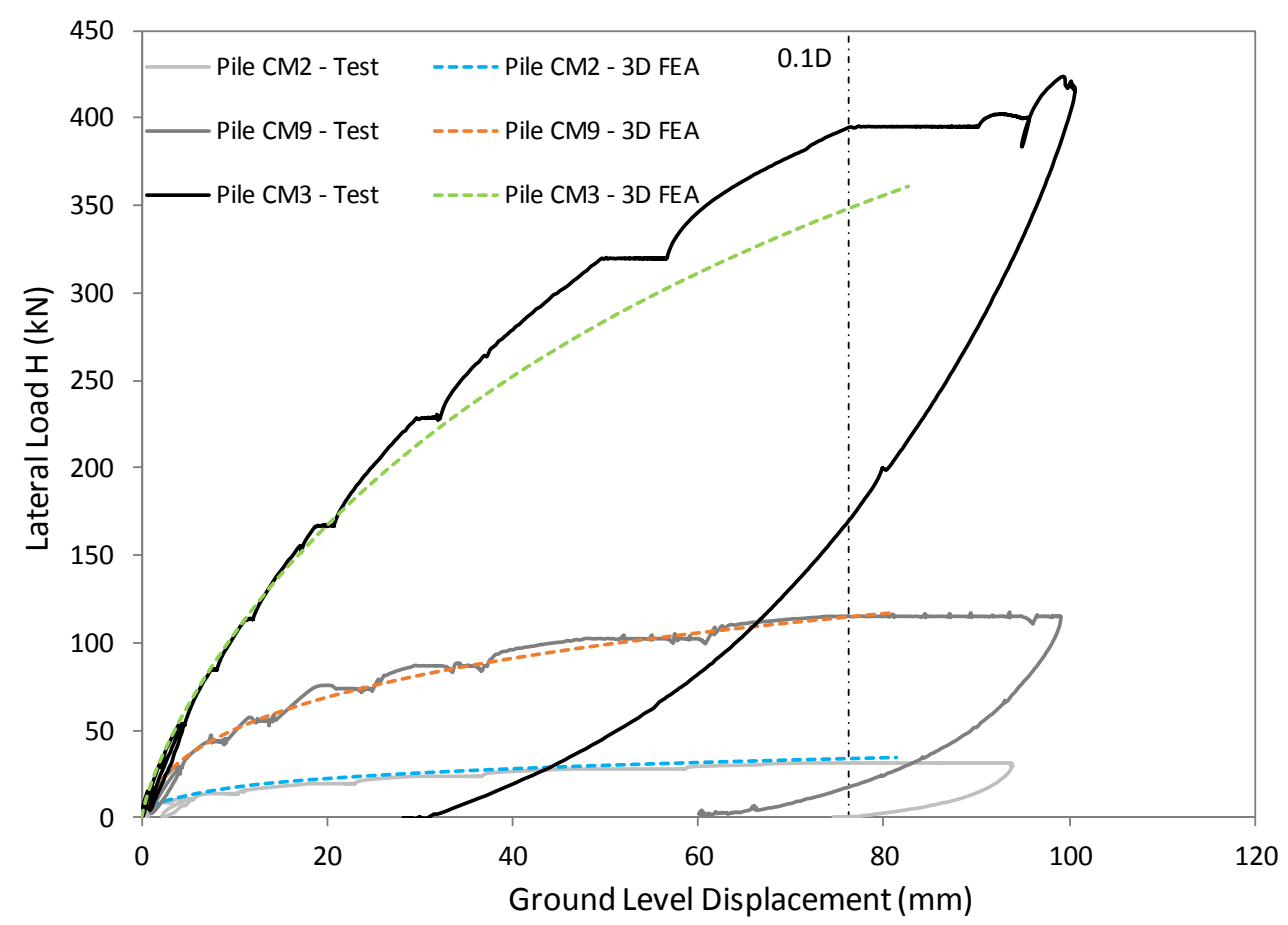

(b)

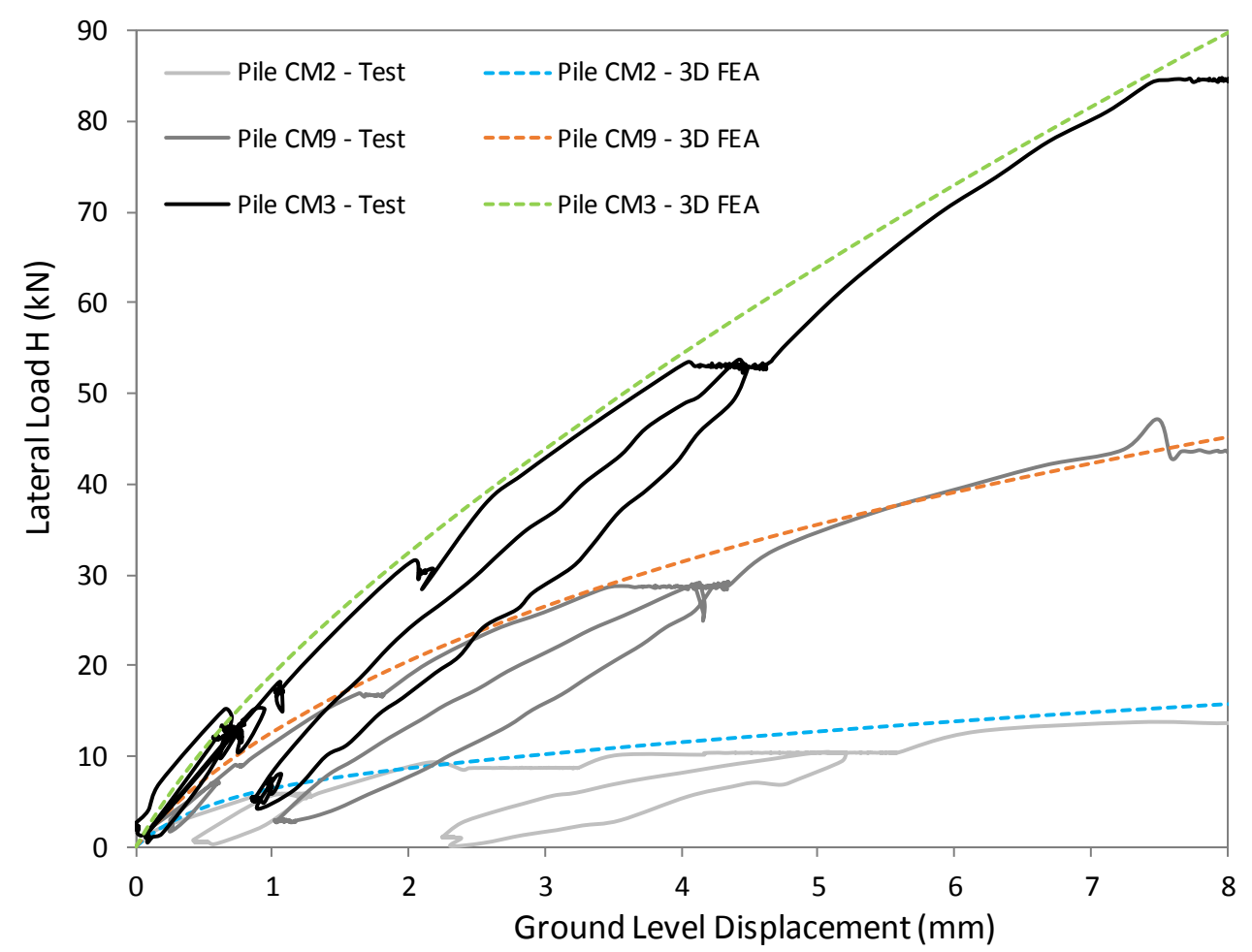

Figure 12: Pile load tests performed at the Cowden test site performed as part of the PISA research project (test data from Byrne et al., 2019) along with 3D FEA predictions using the calibrated PIMS model 

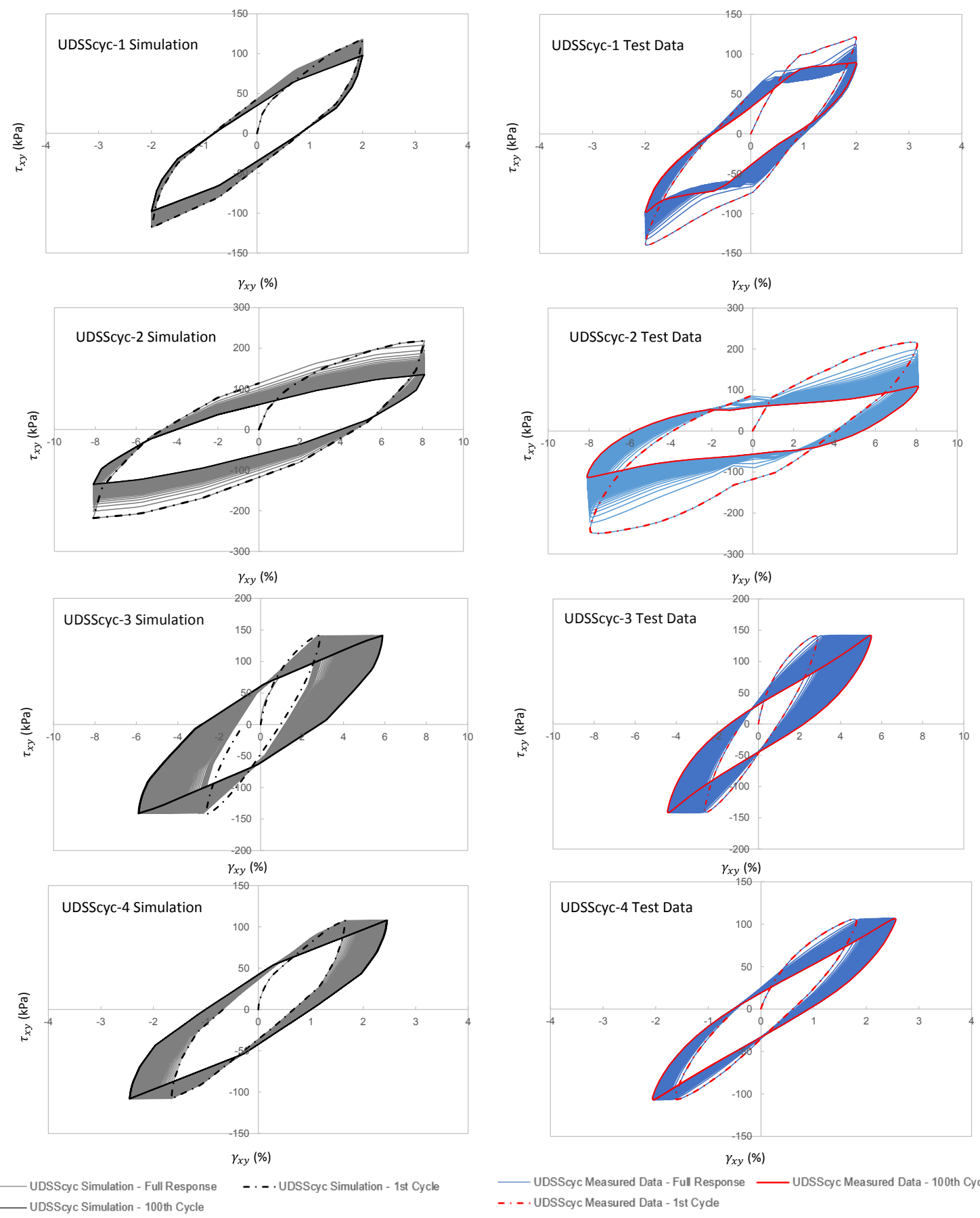

UUDSScyc Measured Data - Full Response _uDSScyc Measured Data - 100th Cycle - - - . UDSScyc Measured Data - 1st Cycle

Figure 13: Measured cyclic undrained direct simple shear tests from Clay Unit A and PIMS model simulations 


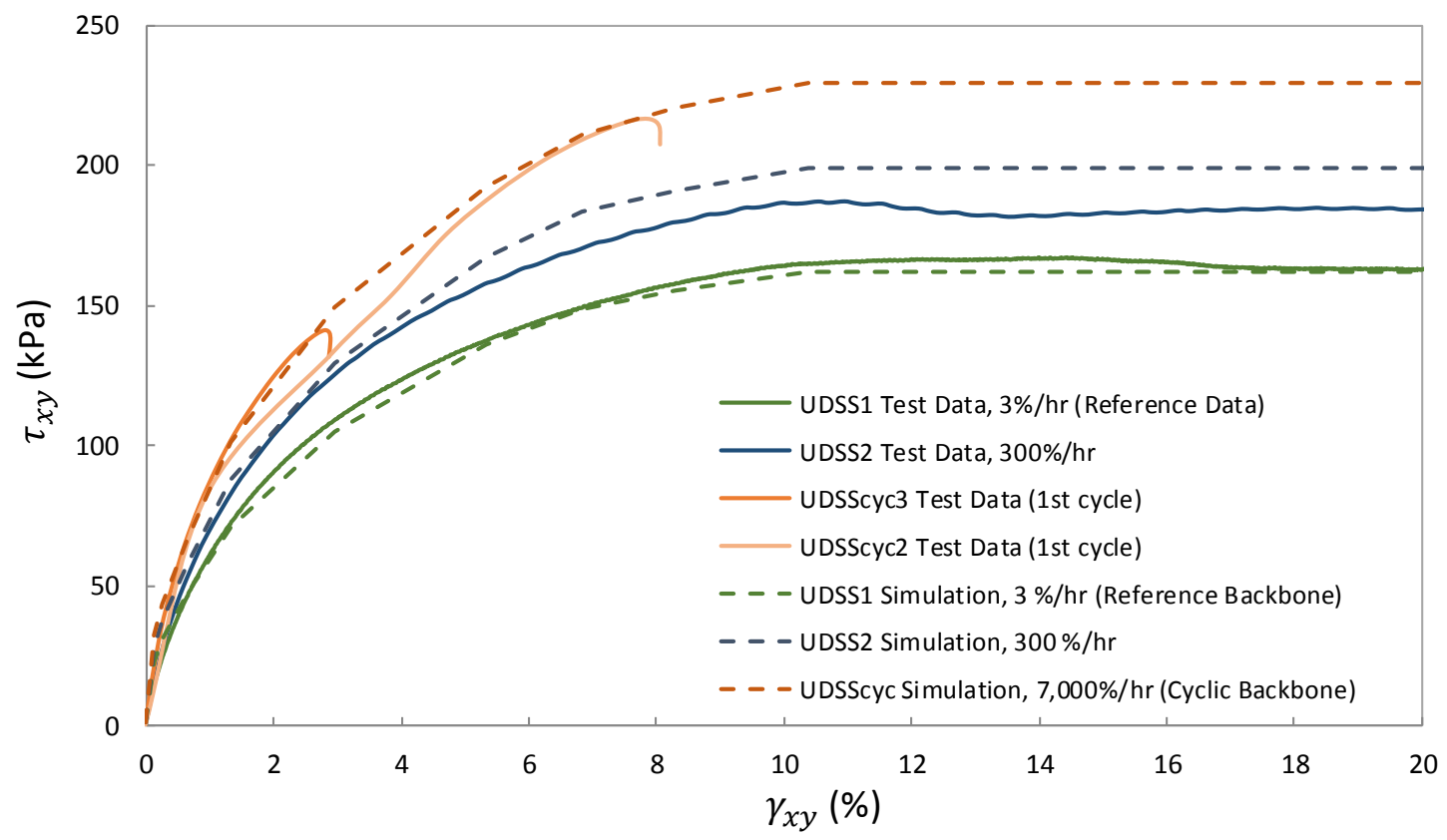

Figure 14: Measured monotonic undrained direct simple shear tests from Clay Unit A and PIMS model simulations for different loading rates

(a)

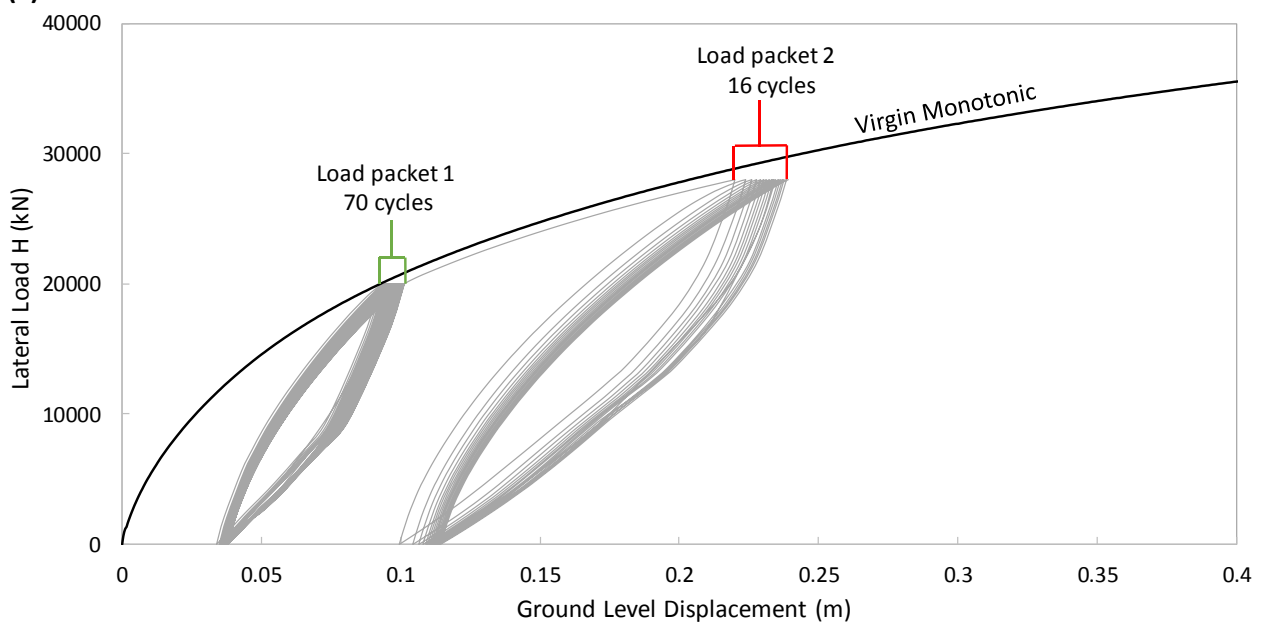

(b)

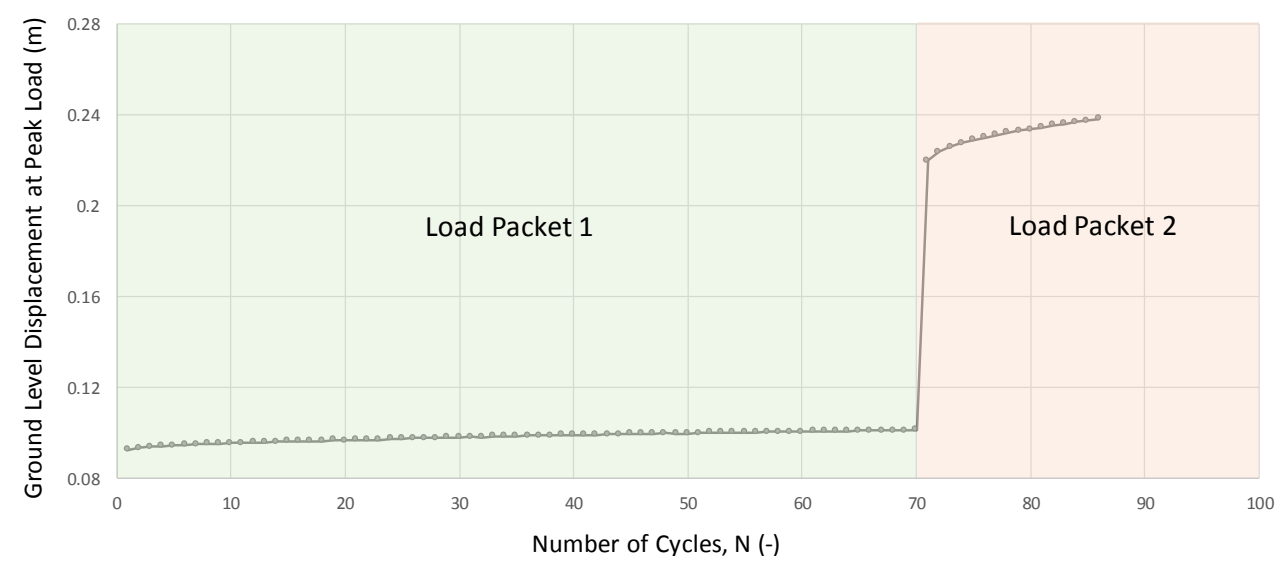

Figure 15: a) Cyclic load-displacement response at ground level and b) lateral displacement accumulation with number of cycles, of a pile with a diameter of $7.5 \mathrm{~m}$ and an embedment length of $\mathbf{2 5} \mathbf{m}$ in a synthetic homogenous soil profile for Clay Unit A 
(a)

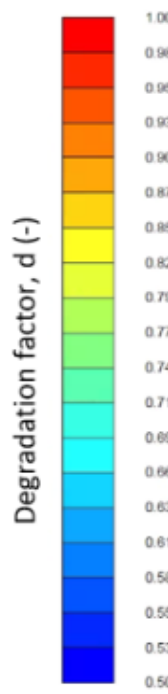

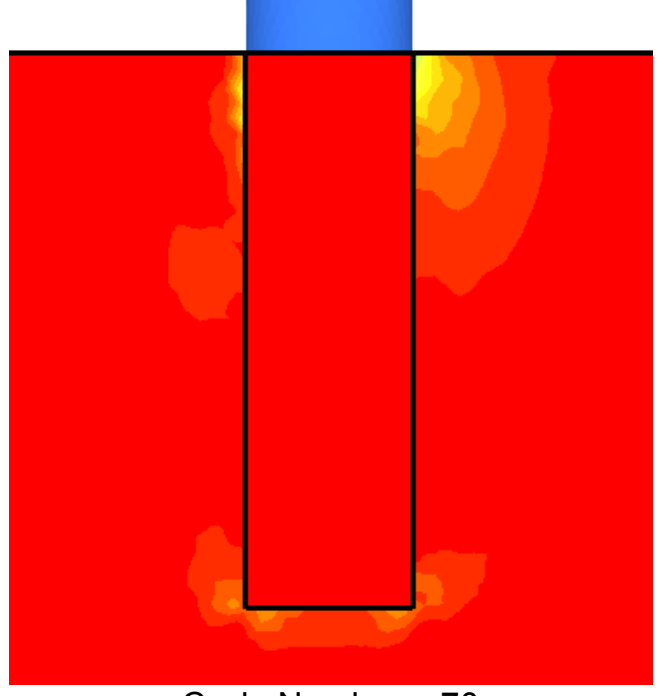

Cycle Number $=70$ (b)

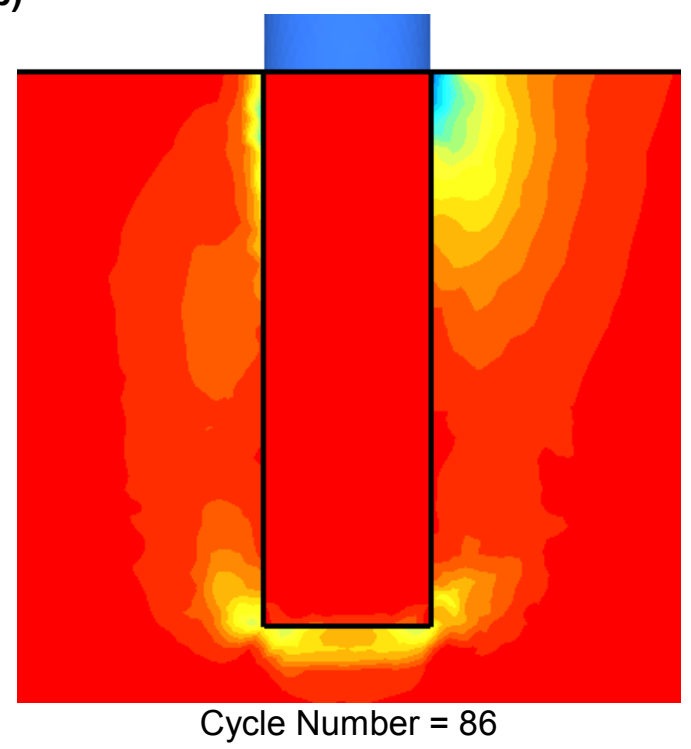

Figure 16: Predicted degradation factor around the pile at the end of load packet 1 and 2 